\title{
Effects of Return Predictability on Option Prices with Stochastic Volatility for the Market Portfolio*
}

\author{
Melanie Cao \\ Schulich School of Business, York University
}

October 4, 2005

\begin{abstract}
I examine the effects of return predictability on option prices for the market portfolio in the presence of stochastic volatility and/or stochastic interest rates. The analysis is implemented in an equilibrium framework where a consistent option pricing model is derived with the return predictability and stochastic volatility and the precise link between the actual and the risk neutral measures is endogenized. The equilibrium analysis indicates that the return predictability is induced by the mean-reverting and heteroskedastic features of aggregate dividends. It is shown that risk-neutral option pricing model with the stochastic volatility and/or stochastic interest rates can be consistent with return predictability. Numerical results suggest that (i) models with either perfect predictability or no predictability will significantly overprice longterm options across different strike prices when the return of the underlying exhibits modest predictability; (ii) the stochastic volatility does not affect option prices in a significant way when asset return predictability is properly reflected in the actual stock price process; (iii) when return predictability is correctly specified, the effects of stochastic interest rates are not uniform.
\end{abstract}

Keywords: Option; Return predictability; Stochastic volatility.

JEL classification: F31.

* Corresponding author: Melanie Cao, Schulich School of Business, York University, 4700 Keele Street, Toronto, Ontario, Canada, M3J 1P3. Telephone: 416-736-2100 ext. 33801. Fax: 416-736-5687. Email: mcao@schulich.yorku.ca. This paper is a revision of a previous paper, "Equilibrium Valuation of Options on the Market Portfolio with Return Predictability and Stochastic Volatility", which has been presented at the Chicago Mercantile Exchange, Queen's and Toronto. I am grateful to Phelim Boyle, Allan Gregory, Ritchie Y. He, John Hull, Robert Jarrow, Raymond Kan, Craig Lewis, Tom McCurdy, Susanne Otruba, Shouyong Shi, Tie Su, Jason Wei and Alan White for valuable comments. Financial support from the Social Sciences and Humanities Research Council of Canada and the Schulich School of Business is gratefully acknowledged. All remaining errors are mine alone. 


\section{Effects of Return Predictability on Option Prices \\ with Stochastic Volatility for the Market Portfolio}

I examine the effects of return predictability on option prices for the market portfolio in the presence of stochastic volatility and/or stochastic interest rates. The analysis is implemented in an equilibrium framework where a consistent option pricing model is derived with the return predictability and stochastic volatility and the precise link between the actual and the risk neutral measures is endogenized. The equilibrium analysis indicates that the return predictability is induced by the mean-reverting and heteroskedastic features of aggregate dividends. It is shown that riskneutral option pricing model with the stochastic volatility and/or stochastic interest rates can be consistent with return predictability. Numerical results suggest that (i) models with either perfect predictability or no predictability will significantly overprice long-term options across different strike prices when the return of the underlying exhibits modest predictability; (ii) the stochastic volatility does not affect option prices in a significant way when asset return predictability is properly reflected in the actual stock price process; (iii) when return predictability is correctly specified, the effects of stochastic interest rates are not uniform.

Keywords: Option; Return predictability; Stochastic volatility.

JEL classfication: F31. 
There exists a fair amount of empirical evidence on asset return predictability and stochastic volatility. ${ }^{1}$ However only the stochastic volatility feature has drawn enough attention from the academic researchers on option pricing. Lo and Wang (1995) is the first study which examines the effects of return predictability on option price while maintaining a constant return volatility. In their study, the return predictability is modeled as a mean-reverting process. Given the common belief that the Black-Scholes (BS) option pricing model is valid in the presence of the return predictability and a constant volatility, they argue that the constant volatility in the BS model should not be estimated from the unconditional standard deviation of the historical returns, a popular approach used in the real world (please see the detailed description in Hull 2005). Instead, it should be estimated from the conditional standard deviation of the historical returns if the risk-neutral return is the BS's log-normal and the actual return follows a mean reverting. ${ }^{2}$

Lo and Wang's study is an important first step towards examining how asset return predictability affects option prices in a context of constant volatility and constant interest rates. The current paper extends their study the market portfolio while allowing both the return predictability and the stochastic volatility. To carry out the analysis, I need to identify an option pricing model which is consistent with the return predictability and stochastic volatility since the BS model is not valid. At the same time, I also need to know the precise link between the risk-neutral distribution and the actual distribution. To ensure the consistency and to obtain the precise link, I derive an option pricing formula based on the assumed actual return dynamics in a general equilibrium framework and establish a precise link between the actual and the risk neutral measures by endogenizing the price of the market portfolio and the risk-free rate from economic fundamentals. The endogenous processes for the market return, its volatility and the interest rate generated from an equilibrium apporach are in sharp contrast to the exgoenous processes assumed by the BS approach. The equilibrium model in the current paper is a continuous-time extension of the Lucas (1978) model where the aggregate dividend follows a mean-reverting process, supported by the empirical evidence in Marsh and Merton (1987). Given this aggregate dividend process and logarithmic preferences, the endogenous return of the market portfolio is mean-reverting and its return volatility, as well as the risk-free rate, is stochastic in equilibrium.

Under various parameter restrictions, this simple one-factor model can generate closed-form option pricing formulas for six useful cases. The generic case corresponds to mean-reverting returns, 
stochastic volatility and stochastic interest rates. Other special cases include mean-return return with a constant volatility and/or a constant interest rate. Given these results, this paper further examines the effects of return predictability on option prices, by allowing for stochastic volatility and/or stochastic interest rates. Since the precise effects cannot be analytically determined, I resort to numerical analysis based on empirically estimated parameters for the six cases in the model. The numerical results show that (i) the cases with either perfect predictability or no predictability significantly overprice long-term options across different strike prices when the return of the underlying asset exhibits moderate predictability; (ii) when return predictability is properly reflected into option prices through the correct specification of the actual return, stochastic volatility does not influence option prices significantly, especially for long-run options; (iii) when return predictability is correctly specified, interest rates influence option prices in a complicated way. For example, the case with stochastic volatility and constant interest rates would underprice longterm options, but overprice short-term options, relative to the case with stochastic volatility and stochastic interest rates.

This paper differs from the existing option pricing studies with stochastic volatility and/or stochastic interest rates, including the models by Hull and White (1987), Stein and Stein (1991), Heston (1993) and Hobson and Rogers (1998). First, the current focus on return predictability is new. Second, volatility and interest rates here are both endogenous variables that depend on economic fundamentals. Third, stochastic volatility here is a function of the stock price, implying that options can be hedged with the underlying stock. This feature is extremely desirable for practical application (see Dupire 1994). Although the feature of complete markets draws a similarity to Hobson and Rogers (1998), their partial equilibrium model contrasts to my general equilibrium model. The equilibrium approach here is shared with Bailey and Stulz (1989) who price stock index options, Bakshi and Chen (1997) who price many different contingent claims, Naik and Lee (1990) who address systematic jump risks in the market portfolio, and Amin and Ng (1993) who focus on systematic volatility in individual stock options. To this literature the current paper contributes mainly in the emphasis on predictability and the explicit analysis of the effects of return predictability on option prices with stochastic volatility and/or stochastic interest rates.

This paper is organized as follows. Section 1 describes the economy and derives the equilibrium price of the market portfolio and the spot interest rate. Section 3 examines the relationship between 
the actual asset price process and its risk-neutral counterpart. Section 3 derives equilibrium pricing formulas for options written on the market portfolio. Section 4 quantifies the effects of return predictability on option prices with stochastic volatility and/or stochastic interest rates. Section 5 concludes the paper and the appendices provide necessary proofs.

\section{The Economy}

\subsection{Structure of the Economy}

Consider a continuous-time extension of the Lucas (1978) pure exchange economy in which there is a representative investor with an infinite lifetime horizon. In the financial market, the representative agent can trade a single risky stock, pure discount bonds and a finite number of other contingent claims at any time. The risky stock can be viewed as the market portfolio, whose total supply is normalized to one share and its dividend stream $\left\{\delta_{t}\right\}$ can be understood as aggregate dividends in the economy. The contingent claims and the risk-free bond are all in zero net supply. The aggregate dividend follows an exogenous Markov process on a given probability space $(\Omega, \mathcal{F}, \mathcal{P})$, which creates the fundamental uncertainty in the economy. Denote the security prices at time $t$ by a vector $X_{t}$ and the corresponding vector of dividends by $q_{t}$. The cumulative dividends up to time $t$ are defined as $D_{t} \equiv \int_{0}^{t} q_{\tau} d \tau$. The agent's information structure is given by the filtration $\mathcal{F}_{t} \equiv \sigma\left(\delta_{\tau}, 0 \leq \tau \leq t\right)$. His preferences are described by a smooth time-additive expected utility function, $V(c)=E \int_{0}^{\infty} U\left(c_{t}, t\right) d t$. For analytical tractability, I adopt a logarithmic utility for the agent's period preference, as in Merton (1971) and Cox-Ingersoll-Ross (1985b):

Assumption 1. The representative agent's period utility is described by $U\left(c_{t}, t\right)=e^{-\rho t} \ln c_{t}$, where $\rho$ is the rate of time preference.

Initially, the agent is endowed with one share of the risky stock. Denote his portfolio holdings at time $t$ as $\theta_{t}=\left(\theta_{t}^{s}, \theta_{t}^{B}, \theta_{t}^{x \prime}\right)$, where $\theta_{t}^{s}, \theta_{t}^{B}$ and $\theta_{t}^{x \prime}$ indicate the number of shares held in the stock, the discount bond and other contingent claims, respectively. The agent finances his consumption by a continuous trading strategy $\left\{\theta_{t}, t \geq 0\right\}$ and maximizes his expected lifetime utility: ${ }^{3}$

$$
\begin{gathered}
\max _{\left\{c_{t}, \theta_{t}\right\}} E \int_{0}^{\infty} U\left(c_{t}, t\right) \mathrm{d} t \\
\text { s.t. } \quad \int_{0}^{t} c_{\tau} \mathrm{d} \tau=\theta_{0} \cdot X_{0}-\theta_{t} \cdot X_{t}+\int_{0}^{t} \theta_{\tau} \cdot \mathrm{d} D_{\tau}+\int_{0}^{t} \theta_{\tau} \cdot \mathrm{d} X \tau .
\end{gathered}
$$


(1.1) states that the agent's cumulative consumption up to $t$ is financed by the net selling of his securities $\left(\theta_{0} \cdot X_{0}-\theta_{t} \cdot X_{t}\right)$ plus the cumulative dividends and cumulative capital gains. The first

order conditions give the usual stochastic Euler equation: $X_{t}=\frac{1}{U_{c}\left(c_{t}, t\right)} E_{t}\left(\int_{t}^{\infty} U_{c}\left(c_{\tau}, \tau\right) \mathrm{d} D_{\tau}\right)$. Thus, the price of any security equals the expected discounted sum of its dividends, with the marginal rate of substitution being the stochastic state price deflator.

In equilibrium, the financial market clears and so the demand for the stock equals the supply of shares, which is one share. Also, equilibrium prices are such that the representative agent holds nothing of the claims other than the risky stock because the corresponding net supply is zero. In addition, the goods market clears so that consumption equals dividends generated from the risky stock. Therefore, the equilibrium price of any security given by the Euler equation becomes

$$
X_{t}=\frac{1}{U_{c}\left(\delta_{t}, t\right)} E_{t}\left(\int_{t}^{\infty} U_{c}\left(\delta_{\tau}, \tau\right) \mathrm{d} D \tau\right), \quad \forall \quad t \in(0, \infty)
$$

\subsection{Mean-Reverting Dividend Process and Return Predictability}

To facilitate discussions and obtain closed form solutions, let us restrict our attention to a specific dividend process for the market portfolio by appealing to the study of Marsh and Merton (1987) on the dynamic behavior of aggregate dividends. Their estimation suggests that changes in the rate of dividend conform with the following description:

$\left(\operatorname{div}_{t}-\operatorname{div}_{t-1}\right) / \operatorname{div}_{t-1}=$ speed of adjustment $\times\left(\right.$ target ratio $\times$ change in stock price $\left.t-\ln \operatorname{div}_{t-1}\right)$.

Their regression results also show that the random components in the change of dividend growth exhibit heteroskedasticity. Based on this empirical evidence, I assume that aggregate dividend follows a mean-reverting process with a positive time trend.

Assumption 2. The aggregate dividend process is governed by the following stochastic process:

$$
\frac{d \delta_{t}}{\delta_{t}}=\left[b_{1}-a_{1}\left(\ln \delta_{t}-u t\right] d t+\sqrt{b_{2}+a_{2}\left(\ln \delta_{t}-u t\right)} d z_{t}\right.
$$

where $z_{t}$ is the standard Wiener process and $a_{1}, a_{2}, b_{1}, b_{2}$ are constant with the restrictions $a_{1}+0.5 a_{2}>0$ and $2\left(a_{1} b_{2}+a_{2} b_{1}-a_{2} u\right) \geq a_{2}^{2}$.

Note that the parameter restrictions in the above assumption are needed to ensure the existence of distributions (see Appendix A.1). Also, when $b_{2}=u=0$, process (1.3) encompasses the single state variable assumed by Cox-Ingersoll-Ross (1985b). 
With Assumptions 1 and 2, the following proposition and corollary summarize equilibrium results for the market portfolio and the instantaneous risk-free rate (see Appendix A for a proof):

Proposition 1.1. The equilibrium price of the market portfolio $S_{t}$, the instantaneous risk-free rate $r_{t}$ and the yield-to-maturity $R(t, T)$ at time $t$ are, respectively

$$
\begin{aligned}
& S_{t}=S\left(\delta_{t}\right)=\delta_{t} / \rho, \\
& r_{t}=\rho+b_{1}-b_{2}-\left(a_{1}+a_{2}\right)\left(\ln \delta_{t}-u t\right), \\
& R(t, T)=\rho+u-v \frac{\ln (A(t, T))}{T-t}-\left[b_{2}+a_{2}\left(\ln \delta_{t}-u t\right)\right] A(t, T)\left(\frac{a_{1}}{a_{2}}+1\right) \frac{1-e^{-\left(a_{1}+a_{2} / 2\right)(T-t)}}{\left(a_{1}+a_{2} / 2\right)(T-t)}, \\
& \text { with } \quad T \text { being the maturity, } \quad \alpha(t, T)=\frac{\left(2 a_{1}+a_{2}\right)}{a_{2}^{2}\left(1-\exp \left(-\left(a_{1}+a_{2} / 2\right)(T-t)\right)\right)}, \\
& \xi=\frac{a_{1} b_{2}+a_{2}\left(b_{1}-u\right)}{a_{1}+0.5 a_{2}}, \quad v=\frac{a_{1}+a_{2} / 2}{a_{2}^{2}} \xi, \quad A(t, T)=\frac{\alpha(t, T) a_{2}}{\alpha(t, T) a_{2}+1} .
\end{aligned}
$$

Proposition 1.1 intuitively states that the stock price equals the present value of future dividends discounted at the rate of time preference. That is, the stock generates a constant dividend yield which is equal to the rate of time preference, $\rho$. Applying Ito's Lemma yields the equilibrium dynamics for the de-trended log price:

$$
\mathrm{d}\left(\ln S_{t}-u t\right)=\left(\bar{b}-\left(a_{1}+\frac{1}{2} a_{2}\right)\left(\ln S_{t}-u t\right)\right) \mathrm{d} t+\sqrt{b_{2}+a_{2}\left(\ln \delta_{t}-u t\right)} d z_{t},
$$

with $\bar{b}=b_{1}-u-\frac{1}{2} b_{2}+\left(a_{1}+\frac{1}{2} a_{2}\right) \ln \rho$. The de-trended log price follows a mean-reverting process with a heteroskedastic volatility structure.

Denote $\mu_{t}$ as the instantaneous return of the stock and $V_{t}$ the instantaneous variance. ${ }^{4}$ Express the endogenous stock price process as $d S_{t} / S_{t} \equiv\left(\mu_{t}-\rho\right) \mathrm{d} t+\sqrt{V_{t}} \mathrm{~d} z_{t}$. Then

$$
\mu_{t}=\rho+b_{1}-a_{1}\left(\ln \delta_{t}-u t\right) \quad \text { and } \quad V_{t}=b_{2}+a_{2}\left(\ln \delta_{t}-u t\right)
$$

Given the instantaneous risk-free rate in Proposition 2.1, it is clear that $\mu_{t}=r_{t}+V_{t}$. That is, the drift of the market portfolio is the sum of the risk-free rate and the variance of its return. In other words, the risk premium of the market portfolio is equal to the variance of its return. Now, let us focus on the dynamics of $r_{t}, \mu_{t}$ and $V_{t}$, respectively. Applying Ito's Lemma yields the spot risk-free rate dynamics:

$$
\mathrm{d} r_{t}=\left(a_{1}+\frac{1}{2} a_{2}\right)\left(\rho+u-\frac{1}{2} \xi-r_{t}\right) \mathrm{d} t-\left(a_{1}+a_{2}\right) \sqrt{V_{t}} \mathrm{~d} z_{t}
$$


The spot risk-free rate obeys a mean-reverting process which resembles the so-called affine class of the term-structure model (see Duffie, 1992). ${ }^{5}$ The reversion speed for the spot risk-free rate is $a_{1}+0.5 a_{2}$ and the long-run mean is $\rho+u-0.5 \xi$. The Vasicek (1977) interest rate model corresponds to $a_{2}=0$ and the Cox-Ingersoll-Ross (1985b) interest rate model to $\rho=-u-\left(2 a_{1} / a_{2}+1\right) \xi$.

The instantaneous return is shown to obey the following process

$$
\mathrm{d} \mu_{t}=\left(a_{1}+\frac{1}{2} a_{2}\right)\left(\rho+u+\frac{1}{2} \xi-\mu_{t}\right) \mathrm{d} t-a_{1} \sqrt{V_{t}} \mathrm{~d} z_{t},
$$

which corresponds to a mean-reverting process with a speed of mean reversion being $a_{1}+0.5 a_{2}$ and a long-run mean being $\rho+u+0.5 \xi$. This reversion speed is different from that of aggregate dividends, $a_{1}$. Thus, the stock return predictability, largely determined by the reversion speed, is generated by the mean-reverting and heteroskedastic features of aggregate dividends. Stated differently, $a_{1}$ and $a_{2}$ determine return predictability for the market portfolio. The higher the reversion speed, $a_{1}+0.5 a_{2}$, the higher the level of return predictability. There are two polar cases of return predictability: perfect predictability (certainty) and complete unpredictability (the random walk). With $a_{1}=0$, the instantaneous return becomes constant and hence is perfectly predictable. With $a_{1}=-0.5 a_{2}$, the instantaneous return follows a random walk with heteroskedastic volatility. When $a_{1} \neq 0$ or $a_{1} \neq-0.5 a_{2}$, the actual instantaneous return shows moderate predictability. Thus, this model is capable of accommodating different degrees of return predictability.

\subsection{The Volatility of the Market Portfolio}

An important feature of the current model is that the volatility dynamics of the market portfolio depends on the dividend drift, despite the fact that the dividend drift and volatility of the market portfolio do not share common parameters. This dependence is evident from the earlier result on the instantaneous variance of the market portfolio, $V_{t}=b_{2}+a_{2}\left(\ln \delta_{t}-u t\right)$. Because the instantaneous variance depends on $\log$ dividends, provided $a_{2} \neq 0$, parameters that affect the dividend drift affect the volatility dynamics of the market portfolio directly through $\delta$. Applying the Ito's lemma, I can obtain the following dynamics of $V$ :

$$
\mathrm{d} V_{t}=\left(a_{1}+\frac{1}{2} a_{2}\right)\left(\xi-V_{t}\right) \mathrm{d} t+a_{2} \sqrt{V_{t}} \mathrm{~d} z_{t}, \quad \forall \quad a_{2} \neq 0 .
$$

Such dynamics are influenced by parameters $a_{1}$ and $b_{1}$, in addition to $a_{2}$ and $b_{2}$. Specifically, the speed of mean reversion is determined by $a_{1}+0.5 a_{2}$ and the long-run mean is by $\xi$, which is a 
function of $\left(a_{1}, b_{1}, a_{2}, b_{2}, u\right)$ as specified in Proposition 2.1. Note that when $a_{1}=0.5 a_{2}$, the meanreverting feature is no longer present; instead, the instantaneous variance follows a random walk. Of course, if $a_{2}=0$, then the instantaneous variance is a constant, $b_{2}$.

The dependence of the variance (or volatility) dynamics of the market portfolio on the dividend drift is not restricted to the specific model in the current paper. Rather, it is a general feature of all models where the volatility of the dividend depends on the dividend level directly. To see this generality, consider the following process for aggregate dividends:

$$
\frac{\mathrm{d} \delta}{\delta}=\mu^{\delta}\left(t, X_{t}, \delta_{t}\right) \mathrm{d} t+\sigma^{\delta}\left(t, \delta_{t}, Y_{t}\right) \mathrm{d} z_{t},
$$

where $\mu^{\delta}\left(t, X_{t}, \delta_{t}\right)$ and $\sigma^{\delta}\left(t, \delta_{t}, Y_{t}\right)$ are the drift and the volatility of dividends and $X, Y$ are two state variables with the following dynamics

$$
\mathrm{d} X=\mu^{X}\left(t, X_{t}\right) \mathrm{d} t+\sigma^{X}\left(t, X_{t}\right) \mathrm{d} z_{t} \quad \text { and } \quad \mathrm{d} Y=\mu^{Y}\left(t, Y_{t}\right) \mathrm{d} t+\sigma^{Y}\left(t, Y_{t}\right) \mathrm{d} z_{t} .
$$

With logarithmic utility, the stock price is still $S_{t}=\delta_{t} / \rho$. As a result, the instantaneous volatility of the market portfolio is equal to that of the dividends. Given the direct dependence of $\sigma^{\delta}$ on $\delta$, the dynamics of the volatility of the market portfolio will be influenced by the dividend drift through $\delta$, as well as by other parameters and the state variables $(X, Y)$. My model captures this direct effect of the dividend drift on the volatility, but it maintains tractability by suppressing the variables $X$ and $Y$. Of course, if $\sigma^{\delta}$ does not depend on $\delta$, then the volatility will not depend on the dividend drift, but this case does not encompass my model as a special case despite the appearance of the state variables $(X, Y)$.

\section{Actual and Risk-Neutral Price Processes for the Market Portfolio}

This section examines the precise relationship between the actual price process and its risk-neutral counterpart for the market portfolio. With the determined precise relation, I will provide answers to the two questions raised in the introduction.

\subsection{Relationship between the Actual Price Process and Its Risk-Neutral Counterpart}

The equivalent martingale process for the market portfolio is obtained as follows: the equilibrium relation, $\mu_{t}=r_{t}+V_{t}$, implies that the risk premium of the stock is equal to its instantaneous 
variance. Thus, the market price of risk of $\mathrm{d} z_{t}$ is $\sqrt{V_{t}}$, derived from the common definition $\left(\mu_{t}-\right.$ $\left.r_{t}\right) / \sqrt{V_{t}}$. Then, the unique equivalent martingale process for the stock price is

$$
\mathrm{d} S_{t}=\left(\mu_{t}-\rho\right) S_{t} \mathrm{~d} t+S_{t} \sqrt{V_{t}} \mathrm{~d} z_{t}=\left(r_{t}-\rho\right) S_{t} \mathrm{~d} t+S_{t} \sqrt{V_{t}} \mathrm{~d} z_{t}^{*}
$$

where $\mathrm{d} z_{t}^{*}=\mathrm{d} z_{t}+\sqrt{V_{t}} \mathrm{~d} t$ is the risk-neutral measure. ${ }^{6}$ With this unique relation $\mathrm{d} z_{t}^{*}=\mathrm{d} z_{t}+\sqrt{V_{t}} \mathrm{~d} t$, the processes for $\mu_{t}, V_{t}$ and $r_{t}$ under the equivalent martingale are

$$
\begin{aligned}
& \mathrm{d} r_{t}=\left(a_{1}+1.5 a_{2}\right)\left(\rho+u-\frac{1}{2} \frac{a_{1}+0.5 a_{2}}{a_{1}+1.5 a_{2}} \xi-r_{t}\right) \mathrm{d} t-\left(a_{1}+a_{2}\right) \sqrt{V_{t}} \mathrm{~d} z_{t}^{*}, \\
& \mathrm{~d} \mu_{t}=\left(a_{1}+1.5 a_{2}\right)\left(\rho+u+\frac{3}{2} \frac{a_{1}+0.5 a_{2}}{a_{1}+1.5 a_{2}} \xi-\mu_{t}\right) \mathrm{d} t-a_{1} \sqrt{V_{t}} \mathrm{~d} z_{t}^{*}, \\
& \mathrm{~d} V_{t}=\left(a_{1}+1.5 a_{2}\right)\left[\frac{a_{1}+0.5 a_{2}}{a_{1}+1.5 a_{2}} \xi-V_{t}\right] \mathrm{d} t+a_{2} \sqrt{V_{t}} \mathrm{~d} z_{t}^{*}, \quad \forall \quad a_{2} \neq 0 .
\end{aligned}
$$

The key difference between the actual processes and the risk-neutral processes for $\mu_{t}, V_{t}$ and $r_{t}$ lies in the speeds of reversion and the corresponding long-run means. Take the variance as an example. The speed of reversion is $a_{1}+0.5 a_{2}$ under the actual probability measure and $a_{1}+1.5 a_{2}$ under the equivalent martingale. In addition, the long-run mean of the variance under the equivalent martingale is $\frac{a_{1}+0.5 a_{2}}{a_{1}+1.5 a_{2}} \xi$, not $\xi$.

To illustrate the importance of a link between the actual and risk-neutral processes for empirical estimation purposes, let us consider the following situation. Suppose one starts with a partial equilibrium model and directly assumes a risk-neutral process for the volatility, like that in (2.1), to price options. To implement his option pricing model, he uses the actual volatility process described in (1.6) to infer the parameters for the risk-neutral process. Suppose that he uses the following parameterization for the risk-neutral and the actual volatility processes:

\begin{tabular}{cc}
\hline Actual Processes & Risk-neutral Processes \\
$V_{t}=a_{V}\left(\bar{V}-V_{t}\right) \mathrm{d} t+b_{V} \sqrt{V_{t}} \mathrm{~d} z_{t}$ & $\mathrm{~d} V_{t}=a_{V}^{*}\left[\bar{V}^{*}-V_{t}\right] \mathrm{d} t+b_{V}^{*} \sqrt{V_{t}} \mathrm{~d} z_{t}^{*}$. \\
\hline
\end{tabular}

Then the estimated parameters for the risk-neutral process should be determined as

$$
b_{V}^{*}=b_{V}, \quad a_{V}^{*}=a_{V}+b_{V}, \quad \bar{V}^{*}=\frac{a_{V}}{a_{V}+b_{V}} \bar{V}
$$

Clearly, this unique link between the actual and the risk-neutral processes for volatility is the equilibrium result. Without this link, it is difficult to correctly identify the parameters for the risk-neutral process from the actual probability distribution. ${ }^{7}$ 


\subsection{Different Levels of Return Predictability}

Under different parameter values, this model can generate three different levels of return predictability: Perfect Predictability, No Predictability and moderate Predictability.

Table 1: Relations among $\mu_{t}, \mathrm{~V}_{t}$ and $\mathrm{r}_{t}$ under Different Levels of Return Predictability

\begin{tabular}{|c|c|c|c|}
\hline & S: S tochastic & I: Interest $\mathrm{R}$ ate & \\
\hline Return has & $\begin{array}{l}\text { C R C V C I - P P }(=\text { B S }) \\
a_{1}=a_{2}=0 \\
b_{1}>0, b_{2}>0\end{array}$ & $\begin{array}{l}\mu_{t}=\rho+b_{1} \\
V_{t}=b_{2} \\
r_{t}=\rho+b_{1}-b_{2}\end{array}$ & $\begin{array}{l}\text { C R } \\
\mathrm{C} \mathrm{V} \\
\mathrm{C} \text { I }\end{array}$ \\
\hline $\begin{array}{l}\text { Perfect } \\
\text { Predictability } \\
\qquad(\text { P P ) }\end{array}$ & $\begin{array}{l}\text { C R S V S I - P P } \\
a_{1}=0 \\
a_{2}>0, \quad b_{2}>0 \\
b_{1}>u+b_{2} / 2\end{array}$ & $\begin{array}{l}\mu_{t}=\rho+b_{1} \\
V_{t}=b_{2}+a_{2}\left(\ln \delta_{t}-u t\right) \\
d V_{t}=0.5 a_{2}\left(\xi-V_{t}\right) d t+a_{2} V_{t}^{1 / 2} d z_{t} \\
r_{t}=\rho+b_{1}-V_{t} \\
d r_{t}=0.5 a_{2}\left(\rho+u-0.5 \xi-r_{t}\right) d t-a_{2} V_{t}^{1 / 2} d z_{t}\end{array}$ & $\begin{array}{l}\text { C R } \\
\text { S V } \\
\text { S I }\end{array}$ \\
\hline $\begin{array}{l}\text { Return has } \\
\text { No Predictability } \\
\quad(\mathrm{N} P)\end{array}$ & $\begin{array}{l}\text { S R S V S I - N P } \\
a_{1}+a_{2} / 2=0 \\
a_{1}>0, \quad b_{2}>0 \\
b_{1}>u+\left(a_{2}+b_{2}\right) / 2\end{array}$ & $\begin{array}{l}\mu_{t}=\rho+b_{1}-a_{1}\left(\ln \delta_{t}-u t\right) \\
d \mu_{t}=0.5 a_{2}\left(b_{1}-0.5 b_{2}-u\right) d t+0.5 a_{2} V_{t}{ }^{1 / 2} d z_{t} \\
V_{t}=b_{2}+a_{2}\left(\ln \delta_{t}-u t\right) \\
d V_{t}=a_{2}\left(b_{1}-0.5 b_{2}-u\right) d t+a_{2} V_{t}{ }^{1 / 2} d z_{t} \\
r_{t}=\rho+b_{1}-0.5 b_{2}-0.5 V \\
d r_{t}=-0.5 a_{2}\left(b_{1}-0.5 b_{2}-u\right) d t-0.5 a_{2} V_{t}{ }^{1 / 2} d z_{t}\end{array}$ & $\begin{array}{l}\text { SR } \\
\text { S V } \\
\text { S I }\end{array}$ \\
\hline & $\begin{array}{l}\text { The Generic Case: } \\
\text { SRSVSI - P } \\
a_{1}+a_{2} / 2>0, a_{1}>0 \\
a_{2} b_{1}+a_{1} b_{2}>a_{2}\left(0.5 a_{2}+u\right)\end{array}$ & $\begin{array}{l}\mu_{t}=\rho+b_{1}-a_{1}\left(\ln \delta_{t}-u t\right) \\
d \mu_{t}=\left(a_{1}+0.5 a_{2}\right)\left(\rho+u+0.5 \xi-\mu_{t}\right) d t-a_{1} V_{t}{ }^{1 / 2} d z_{t} \\
V_{t}=b_{2}+a_{2}\left(\ln \delta_{t}-u t\right) \\
d V_{t}=\left(a_{1}+0.5 a_{2}\right)\left(\xi-V_{t}\right) d t+a_{2} V_{t}{ }^{1 / 2} d z_{t} \\
r_{t}=\rho+b_{1}-b_{2}-\left(a_{1}+a_{2}\right)\left(\ln \delta_{t}-u t\right) \\
d r_{t}=\left(a_{1}+0.5 a_{2}\right)\left(\rho+u-0.5 \xi-r_{t}\right) d t-\left(a_{l}+a_{2}\right) V_{t}{ }^{1 / 2} d z_{t}\end{array}$ & $\begin{array}{l}\text { S R } \\
\text { S V } \\
\text { S I }\end{array}$ \\
\hline $\begin{array}{l}\text { Return has } \\
\text { moderate } \\
\text { Predictability } \\
\quad(P)\end{array}$ & $\begin{array}{l}\text { S R S V C I - P } \\
a_{1}=-a_{2}>0 \\
u+0.5 b_{2}<b_{1}<u+b_{2}-0.5 a_{1}\end{array}$ & $\begin{array}{l}\mu_{t}=\rho+b_{1}-a_{1}\left(\ln \delta_{t}-u t\right) \\
d \mu_{t}=0.5 a_{1}\left(\rho+u+0.5 \xi-\mu_{t}\right) d t-a_{1} V_{t}^{1 / 2} d z_{t} \\
V_{t}=b_{2}-a_{1}\left(\ln \delta_{t}-u t\right) \\
d V_{t}=0.5 a_{1}\left(\xi-V_{t}\right) d t-a_{1} V_{t}^{1 / 2} d z_{t} \\
r_{t}=\rho+b_{1}-b_{2}\end{array}$ & $\begin{array}{l}\mathrm{S} \mathrm{V} \\
\mathrm{C} \mathrm{I}\end{array}$ \\
\hline & SR C V S I - P & $\begin{array}{l}\mu_{t}=\rho+b_{1}-a_{1}\left(\ln \delta_{t}-u t\right) \\
d \mu_{t}=a_{1}\left(\rho+u+0.5 \xi-\mu_{t}\right) d t-a_{l} V_{t}^{1 / 2} d z_{t}\end{array}$ & S R \\
\hline & $\begin{array}{l}a_{2}=0 \\
a_{1}, b_{1}, b_{2}>0\end{array}$ & $\begin{array}{l}V_{t}=b_{2} \\
r_{t}=\rho+b_{1}-b_{2}-a_{1}\left(\ln \delta_{t}-u t\right) \\
d r_{t}=a_{1}\left(\rho+u-0.5 \xi-r_{t}\right) d t-a_{1} V_{t}^{1 / 2} d z\end{array}$ & $\mathrm{CV}$ \\
\hline
\end{tabular}

Combined with the return volatility and the interest rate, there are six cases of the model listed in Table 1: CRCVCI-PP and CRSVSI-PP under Perfect Predictability, SRSVSI-NP under No Predictability and SRSVSI- $P$, SRSVCI- $P$ and SRCVSI- $P$ under moderate Predictability. The first case CRCVCI-PP corresponds to the BS's risk-neutral model where the interest rate and the volatility of the asset are constant. At the same time, the return is also constant. The second case 
CRSVSI-PP indicates a constant return, stochastic volatility and a stochastic interest rate. It shows that stochastic volatility and stochastic interest rates can be consistent with perfect predictability. The third case SRSVSI-NP stands for stochastic return, stochastic volatility and stochastic interest rate, none of which is predictable. The fourth case SRSVSR-P is the generic case where the return has moderate predictability with stochastic and mean-reverting $V_{t}$ and $r_{t}$. The fifth case SRSVCI$\mathrm{P}$ permits return predictability and stochastic volatility while preserving a constant interest rate. The sixth case SRCVSI-P permits return predictability and stochastic interest while preserving constant volatility. In summary, the cases with stochastic volatility and/or stochastic interests (e.g., SRSVSI-P SRCVSI-P SRSVCI-P) are consistent with return predictability for the market portfolio.

It is important to note that the degree of return predictability under the actual probability measure is not necessarily the same as that under the risk-neutral measure. Table 2 summarizes parameter restrictions and the corresponding degrees of return predictability under both measures. The degrees of predictability in most cases are similar except the no-predictability cases. When $a_{1}+0.5 a_{2}=0$, the return has no predictability under the actual measure while it is predictable under the risk neutral measure. On the other hand, when $a_{1}+1.5 a_{2}=0$, the return has no predictability under the risk neutral measure while it is predictable under the actual measure.

Table 2: Level of Return Predictability under the Actual and the Risk-Neutral Measures

\begin{tabular}{|c|c|c|}
\hline C: Constant & S: S to & $\mathrm{R}$ : Return \\
\hline
\end{tabular}

\begin{tabular}{|c|c|c|}
\hline Parameter Restrictions & Under the Actual Probability Measure & Under the Risk-Neutral M easure \\
\hline$a_{1}=a_{2}=0$ & CRCVCI - PP & CRCVCI - PP \\
\hline$a_{1}=0$ & CRSVSI - PP & CRSVSI - PP \\
\hline$a_{1}+a_{2} / 2=0$ & SRSVSI - NP & SRSVSI - P \\
\hline$a_{1}+3 a_{2} / 2=0$ & SRSVSI - P & SRSVSI -NP \\
\hline The generic case & SRSVSI - P & SRSVSI - P \\
\hline$a_{1}=-a_{2}$ & SRSVCI - P & SRSVCI - P \\
\hline$a_{2}=0$ & SRCVSI - P & SRCVSI - P \\
\hline
\end{tabular}




\section{Pricing European Options on the Market Portfolio}

I now examine the option prices under different parameter restrictions. Consider a European call option written on the market portfolio with a strike price $K$ and a maturity $T$. Its price at time $t \leq T, C_{t}\left(S_{t}, K, T\right)$, can be determined through the Euler equation (1.2) as

$$
C_{t}\left(S_{t}, K, T\right)=E_{t}\left(\frac{U_{c}\left(c_{T}, T\right)}{U_{c}\left(c_{t}, t\right)} \max \left(S_{T}-K, 0\right)\right)=e^{-\rho(T-t)} \delta_{t} E_{t}\left(\frac{1}{\delta_{T}} \max \left(S_{T}-K, 0\right)\right) .
$$

To simplify the presentation of equilibrium option pricing formulas, denote

$$
\chi(a, b, c) \equiv \sum_{j=0}^{\infty} \frac{e^{-a} a^{j}}{j !} \frac{\Gamma(b+j, c)}{\Gamma(b+j)}, \quad \text { and } \quad 1-\chi(a, b, c) \equiv \sum_{j=0}^{\infty} \frac{e^{-a} a^{j}}{j !} \frac{\gamma(b+j, c)}{\Gamma(b+j)}
$$

where $\Gamma(a, x) \equiv \int_{x}^{\infty} e^{-y} y^{a-1} d y$ and $\gamma(a, x) \equiv \int_{0}^{x} e^{-y} y^{a-1} d y$ for positive $x$ and $\gamma(a, x)+\Gamma(a, x) \equiv$ $\Gamma(a)$. The following proposition states the European stock option price formulas for the six cases identified in Table 1 (see Appendix B for a proof).

Proposition 3.1. The equilibrium option prices on the market portfolio are:

$$
\begin{aligned}
& \text { For } a_{2}>0, \quad C_{t}\left(S_{t}, K, T\right)=S_{t} e^{-\rho(T-t)} \chi_{1}-K e^{-R(t, T)(T-t)} \chi_{2} \\
& \text { with } \quad d(K)=V_{t}-a_{2}\left[\ln S_{t} / K+u(T-t)\right] \text {; } \\
& \chi_{1}=\chi\left(\alpha(t, T) V_{t} e^{-\left(a_{1}+0.5 a_{2}\right)(T-t)}, v, \alpha(t, T) d(K)\right) \\
& \chi_{2}=\chi\left(A(t, T) \alpha(t, T) V_{t} e^{-\left(a_{1}+0.5 a_{2}\right)(T-t)}, v, \frac{\alpha(t, T)}{A(t, T)} d(K)\right) . \\
& \text { For } a_{2}<0, \quad C_{t}\left(S_{t}, K, T\right)=S_{t} e^{-\rho(T-t)}\left(1-\chi_{1}\right)-K e^{-R(t, T)(T-t)}\left(1-\chi_{2}\right) \text {. } \\
& \text { For } a_{2}=0, \quad C_{t}\left(S_{t}, K, T\right)=S_{t} e^{-\rho(T-t)} N\left(d_{1}\right)-K e^{-\bar{R}(t, T)(T-t)} N\left(d_{2}\right), \\
& \text { with } \quad \bar{R}(t, T)=\lim _{a_{2} \rightarrow 0} R(t, T), \quad \Sigma=\sqrt{b_{2} \frac{1-e^{-2 a_{1}(T-t)}}{2 a_{1}(T-t)}}, \\
& d_{1}=\frac{\ln S_{t} / K+\left(\bar{R}(t, T)-\rho+\frac{1}{2} \Sigma^{2}\right)(T-t)}{\Sigma \sqrt{T-t}} \quad \text { and } \quad d_{2}=d_{1}-\Sigma \sqrt{T-t}
\end{aligned}
$$

The corresponding European put prices can be computed from the put-call parity condition with $\rho$ as the constant dividend yield. 
Formula (4.1) is applicable to the perfectly predictable case CRSVSI-PP and the no-predictability case SRSVSI-NP. Formula (4.2) is applicable to the constant interest rate case SRSVCI-P with return predictability. Depending on the sign of $a_{2}$, the generic case SRSVSI-P can use either (4.1) or (4.2). Finally, (4.3) is applicable to the constant volatility case SRCVSI-P with return predictability. In the limit $a_{1}+0.5 a_{2} \rightarrow 0$, (4.3) reduces to the case CRCVCI-PP or the BS model. Note that the option formulas in Proposition 4.1 can also be derived through the equivalent martingale pricing principle with the unique transformation $\mathrm{d} z_{t}^{*}=\mathrm{d} z_{t}+\sqrt{V_{t}} \mathrm{~d} t .^{8}$

The generic case SRSVSI-P incorporates moderate return predictability, while allowing for stochastic volatility and stochastic interest rates. The probability of exercising an option at maturity is described by a non-central $\chi^{2}$ distribution which captures the skewness and kurtosis of the return for the market portfolio much better than a normal distribution. From a practical point of view, option prices in (4.1) and (4.2) can be easily computed since $\Gamma$ functions are readily available in many software packages.

It is inappropriate to provide a direct comparison between the current model and Lo and Wang's (1995) analysis, since the former allows for stochastic volatility and/or stochastic interest rate and the latter deals with constant interest rates and constant volatility. The closest case is SRCVSI-P with $a_{2}=0$, which permits constant volatility but stochastic risk-free rates. SRCVSI-P corresponds to formula (4.3). It is clear that parameter $a_{1}$ affects the probability calculation $N\left(d_{1}\right)$ and $N\left(d_{2}\right)$ through the volatility-to-maturity $\Sigma=\left[b_{2}\left(1-e^{-2 a_{1}(T-t)}\right) /\left(2 a_{1}(T-t)\right)\right]^{1 / 2}$.

As expected, the risk-free yield, not the drift of the market portfolio, explicitly enters option pricing formulas in (4.1), (4.2) and (4.3) as the discount rate. However, it would be erroneous to infer that parameters determining return predictability $\left(a_{1}\right.$ and $\left.a_{2}\right)$ do not affect option prices for the market portfolio. They affect option prices through the endogenous stochastic volatility and the risk-free yield. This result is quite different from that in Lo and Wang (1995), who conclude that return predictability influences only the volatility parameter. The difference arises for two reasons: (i) because the current model uses an equilibrium framework where interest rates endogenously depend on parameters underlying the aggregate dividend process; (ii) the asset under consideration is the market portfolio, not individual stocks. ${ }^{9}$

However, parameters $\left(a_{1}\right.$ and $\left.a_{2}\right)$ that determine return predictability affect stochastic volatility and the risk-free yield in a very complicated way, which makes it difficult to analytically determine 
their overall effects on option prices. Therefore, I quantify the effects with numerical analysis in the next section.

\section{Empirical Estimation and Numerical Analysis}

I conduct numerical analyses in two steps. First, I empirically estimate the model parameters. Second, with the estimated parameters, I calculate option prices for the six cases and identify the effects of return predictability under different conditions.

\subsection{Parameter Estimation for S\&P500}

The S\&P500 is taken as a proxy for the market portfolio. The model parameters are estimated through the price movements described in (1.4). The S\&P 500 daily ex-dividend closing prices are obtained from Bloomberg for the period of January 1, 1979 to December 31, 1998 and are used to estimate parameters $\left(u, a_{1}, b_{1}, a_{2}, b_{2}\right) .{ }^{10}$ The rate of time preference, $\rho$, is equal to the dividend yield on the market portfolio in equilibrium; so it is set to be $2.5 \%$ to match the long-run average dividend yield of S\&P500. The daily return file is first created by computing $\ln S_{t} / S_{t-1}$ from the daily price data. Based on the daily return file, weekly, monthly and quarterly returns and the corresponding variances are created. For example, the weekly return is the sum of the daily returns for a week. The corresponding variance is the variance of the daily return during the week. The implicit assumption is that the variance is constant during the week but changes from week to week, as in Wiggins (1987). It is important to note that the return is negatively correlated with its variance for all horizons. The negative correlation ranges from -.22276 for the weekly data to -.41843 for the quarterly data. The negative correlation confirms a similar result in Cox (1996), Das and Sundaram (1999), Wiggins (1987) and many others. ${ }^{11}$

To begin with the estimation, I first de-trend the log stock price. The OLS regression shows that S\&P500 was growing at a rate of $11 \% \sim 12 \%$ during 1979 - 1998. In the estimation, I utilize the de-trended log price in (1.4) and the equilibrium restriction on volatility, i.e., $V_{t}=$ $b_{2}+a_{2}\left(\ln S_{t}-\ln \rho-u t\right)$. Maximum likelihood method is performed with weekly, monthly and quarterly data. Table 3 presents the estimation results for model parameters $\left(u, a_{1}, b_{1}, a_{2}, b_{2}\right)$ under the six cases identified in Table 1. A few observations are in order.

(1) For the generic case SRSVSI-P, the estimated parameters are sensitive to return horizons. 
Notably, parameter $a_{1}$, a key parameter determining the reversion speed, increases from 0.06967 with the weekly horizon to 0.43332 for the quarterly horizon. This suggests that return predictability is more pronounced for longer horizons.

(2) The cases with modest predictability, SRSVCI-P and SRCVSI-P are the restricted versions of the generic case SRSVSI-P. In order to guarantee a similar behavior of the volatility structure, I set the long-run means of the volatility in these two restrictive cases to be equal to that of the generic case SRSVSI-P. The estimated $a_{1}$ under SRCVSI-P is usually bigger than that of the generic case SRSVSI-P. Such a larger magnitude of $a_{1}$ may be a result of compensating for the constant volatility restriction. SRSVCI-P is the most restrictive case, which requires $a_{2}=-a_{1}$. This restriction forces $a_{2}$ to take a negative value which imposes a positive relation between the return and its variance. This imposed positive relation contradicts the true negative relation as shown in the data.

(3) Under CRSVSI-PP where the instantaneous return is constant, the estimated long-run mean of volatility is bigger than that of the generic case SRSVSI-P. Consequently, it may imply a higher expected stock price compared with the generic case which has a lower long-run mean of volatility, as shown in the numerical comparison.

(4) The no-predictability case SRSVSI-NP restricts the reversion speed to be zero. As a result, the estimated $b_{1}$ under this case is significantly higher than that of the generic case SRSVSI-P.

The analysis below is carried along two dimensions. Section 5.2 investigates the effects of different levels of return predictability on option prices in a Stochastic-Volatility-Stochastic-Interest-Rate context. Namely, I contrast the perfect predictability case CRSVSI-PP and the no-predictability case SRSVSI-NP to the generic case SRSVSI-P with a moderate predictability. Section 5.3 examines the effects of stochastic volatility or stochastic interest rates on option prices when actual returns exhibit modest predictability. This analysis is carried out with SRSVCI-P, SRCVSI-P and the generic case SRSVSI-P. In addition, I make comparisons to the BS model (or the CRCVCI-PP case) throughout the analysis.

\subsection{Effects of Predictability on Option Prices with Stochastic Volatility and Stochastic Interest Rate}

This section analyzes the effects of different degrees of return predictability on option prices in a SVSI environment. CRSVSI-PP, SRSVSI-NP and the generic case SRSVSI-P all allow for stochastic 
volatility and stochastic interest rate. To follow the standard practice, I compare these three cases with the modified-BS option prices which are defined as follows: the constant volatility and the constant interest rate in the BS model are replaced with the volatility term structure and yield curve for different maturities. It explicitly incorporates non-constant volatility and non-constant interest rate into the $\mathrm{BS}$ model. ${ }^{12}$ In addition, CRCVCI-PP is taken as a benchmark case and is strictly computed with a constant interest rate and constant volatility.

Call and put option prices are calculated for a short maturity $T-t=0.25$ year, a medium maturity $T-t=1$ year and a long maturity $T-t=5$ years. Strikes are chosen so that the moneyness of an option is linked to the expected index level, not the spot index level, for a specific maturity under each case. For example, the out-of-the-money call option strike is set at $K=0.95 E_{t}\left(S_{T}\right)$ while the in-the-money call option strike at $K=1.05 E_{t}\left(S_{T}\right)$ and the at-the-money call option strike at $K=E_{t}\left(S_{T}\right)$. There are two important reasons for doing so. First, it is not appropriate to set the same strike price for different maturities for the same case. Given the positive growth trend in the stock return, the index is likely to increase more in a long horizon than in a short horizon. This would suggest that a longer-maturity option would more likely be in the money if the moneyness were defined by the spot index and hence would create some "systematic" bias towards longer-maturity option prices in the same case. The proposed adjustment of moneyness eliminates this bias. For comparison, I examine the percentage price differences, not the price differences. The percentage price is calculated as the ratio between the option price and the spot index. In this way, I can effectively illustrate the impact of different maturities on options under the same level of return predictability. Second, it is not proper to set the same strikes across different cases for the same maturity since each of the six cases permits different price dynamics for the stock. The adjusted moneyness for each strike permits a fair comparison based on the percentage pricing differences between different cases for the same maturity, and hence effectively demonstrates the influence of different levels of return predictability on options under the same maturity.

For all calculations, the spot index level is set at $S_{t}=1300$, which resembles the average level in the sample period. The conditional expected stock prices, $E_{t}\left(S_{T}\right)$, derived in Appendix C, are also computed for each case. Tables 4 and 5 compare call/put options among CRCVCI-PP, CRSVSI-PP, SRSVSI-NP and the generic case SRSVSI-P. Each table contains option prices and delta hedging ratios for each case with three maturities and three strikes. ${ }^{13}$ The modified-BS option 
value is computed for each case and each maturity, according to the procedure defined earlier. I summarize the general results as follows.

(1) The conditional expected stock prices, $E_{t}\left(S_{T}\right)$, are very similar across different cases for short horizons. For example, the 3-month conditional expected stock prices implied by these 4 cases range from 1371.46 to 1376.62 . However, as the horizon gets longer, the differences among these four cases become larger. For the maturity $T-t=1$ year, the conditional expected stock prices range from 1500.00 to 1527.17 . For the maturity $T-t=5$ years, the conditional expected stock prices range from 2373.27 to 2689.18 . In general, the generic case SRSVSI-P always yields the lowest expected stock price while SRSVSI-NP gives the highest, which may be attributed to the no-predictability feature and the higher long-run mean of volatility.

(2) For the interest rate structure, CRSVSI-PP, SRSVSI-NP and SRSVSI-P generate upward sloping yield curves. For the volatility structure, only the generic case SRSVI-P generates a realistic downward sloping volatility structure while CRSVSI-PP and SRSVSI-NP generate unrealistic upward sloping volatility structure.

(3) The modified-BS call price for each maturity and each strike is computed. It is almost always higher than the option price for the corresponding case. This suggests that the modified-BS approach described here would generally overprice options.

(4) The percentage option prices with short maturity are very similar under CRCVCI-PP, CRSVSI-PP, SRSVSI-NP and the generic case SRSVSI-P. For example, the at-the-money call prices with maturity $T-t=0.25$ year range from $2.694 \%$ and $2.862 \%$ of the spot index while the corresponding put option prices range between $3.25 \%$ and $3.481 \%$. However, the percentage price difference gets larger as maturity increases. For the maturity $T-t=1$ year, the at-the-money call prices range from $4.23 \%$ to $5.074 \%$ while the at-the-money put prices from $5.815 \%$ to $7.561 \%$. The difference is even larger for options with maturity $T-t=5$ years. The at-the-money call prices range from $4.606 \%$ to $7.912 \%$ while the corresponding put prices from $6.956 \%$ to $20.566 \%$. These patterns are illustrated in Exhibit 1. Under all circumstances, the generic case SRSVSI-P almost always generates the lowest call prices, implying that call options would be overpriced by the modified-BS, or CRCVCR-PP, CRSVSI-PP and SRSVSI-NP which did not correctly reflect the level of return predictability.

(5) Since the one-factor set-up in the current model allows for a perfect hedge with the un- 
derlying stock in a SVSI context, it is interesting to examine the implication of delta hedging in the presence of return predictability. Tables 4 and 5 show that delta hedge ratios for options with short-maturity are similar for different levels of return predictability. In particular, the delta ratio ranges from 0.4467 to 0.4971 for the at-the-money call option, and from -0.4314 to -0.5112 for the at-the-money put option. The difference in the delta hedging ratio gets larger as the maturity increases. More precisely, for the medium maturity, the delta ratio ranges from 0.3250 to 0.4810 for the at-the-money call option, from -0.2680 to -0.5159 for the at-the-money put option. For the long maturity, the delta ratio ranges from 0.0806 to 0.3960 for the at-the-money call option, and from -0.2150 to -0.4982 for the at-the-money put option. The generic case requires the least percentage of the underlying stock to hedge a call. These observations are illustrated in Exhibit 2.

It is worth noting that the differences in delta ratio across difference cases are generally much larger than the differences in prices. This observation has important implications for hedging practice. For example, when delta hedging is carried out based on a wrong model, the hedging errors can be significant even if the prices generated by this model is close to the "correct" prices. Take the 1-year at-the-money call options as an example. The delta ratios are 0.325, 0.469 and 0.481 under SRSVSI-P, CRSVSI-PP and SRSVSI-NP, respectively. Suppose the SRSVSI-P case is correct, the unnecessary hedging costs for each call option are $\$ 187.2(=1300 *(0.469-0.325))$ under CRSVSI-PP and $\$ 202.8=(1300 *(0.481-0.325))$ under SRSVSI-NP. Stated differently, the unnecessary hedging costs are worth $14.4 \%(=187.2 / 1300)$ of the stock index under CRSVSI-PP, or $15.6 \%(=202.8 / 1300)$ under SRSVSI-NP.

In summary, the numerical results show that if the level of return predictability is not properly reflected, long-term options will be significantly overpriced in a SVSI environment.

\subsection{Effects of Volatility and Interest Rate Under Moderate Return Predictability}

This section analyzes the effects of SV and/or SI on option prices when actual returns exhibit modest predictability. Namely, I compare the constant volatility cases SRCVSI-P and the constant interest rate case SRSVCI-P with the generic case SRSVSI-P. Tables 6 and 7 present the comparisons for calls and puts, respectively. Similar to Tables 4 and 5, they contain option prices and delta hedging ratios for each case with three maturities and three strikes. In addition, the modified-BS option value is also computed. The general results can be summarized as follows. 
(1) The conditional expected stock prices, $E_{t}\left(S_{T}\right)$, are very similar across different cases for short horizons. As the horizon gets longer, the differences among the three cases become larger. The generic case SRSVSI-P yields the modest expected stock level. SRSVCI-P always gives the lowest prediction. This may be a result of the incorrect correlation between returns and the variances imposed by a negative $a_{2}$.

(2) This constant interest rate case SRSVCI-P generates an unrealistic upward sloping volatility structure. Such unrealistic volatility structures have direct consequences on the option prices. As shown by the numerical results, long-term options with 5 -year maturity calculated by SRSVCI-P are much lower than those given by the generic case SRSVSI-P. However, for in-the-money shortterm options, SRSVCI-P gives higher prices than the generic case SRSVSI-P. Similar observations can be made for delta hedging ratios.

(3) The constant volatility case SRCVSI-P produces very similar percentage option prices to those of the generic case SRSVSI-P. For the short maturity at-the-money call option, the percentage price is $2.706 \%$ under SRCVSI-P and $2.712 \%$ under the generic case SRSVSI-P. For the medium maturity at-the-money call option, the percentage price is $4.248 \%$ under SRCVSI-P and $4.23 \%$ under the generic case SRSVSI-P. For the long maturity at-the-money call option, the percentage price is $4.692 \%$ under SRCVSI-P and $4.606 \%$ under the generic case SRSVSI-P. In terms of delta hedging, the constant volatility case SRCVSI-P and the generic case SRSVSI-P behave very similarly. For example, the delta hedging ratio for the short maturity at-the-money call option is 0.4316 under SRCVSI-P and 0.4467 under the generic case SRSVSI-P. For the medium maturity at-the-money call option, the hedging ratio is 0.3043 under SRCVSI-P and 0.3250 under the generic case SRSVSI-P. For the long maturity at-the-money call option, the hedging ratio is 0.0802 under SRCVSI-P and 0.0868 under the generic case SRSVSI-P.

In summary, the two-dimensional comparisons in Sections 5.2 and 5.3 suggest that (i) stochastic volatility does not influence European option prices or the hedging ratios in a significant way when moderate predictability is properly reflected in option prices through the correct specification of the actual returns; ${ }^{14}$ and (ii) when return predictability is correctly specified, interest rates affect the option prices in a more complicated way. If the interest rate were assumed constant, the model with stochastic volatility would underprice the long-term options while overpricing short-term inthe-money options. 


\section{Conclusion}

This paper examines the effects of return predictability on option prices in the presence of stochastic volatility and/or stochastic interest rates. The analysis is carried out in a general equilibrium framework where the option pricing formula is derived with the return predictability and stochastic volatility and the precise link between the actual and the risk neutral measures is endogenized. Five important results are established. First, equilibrium results indicate that return predictability of the market portfolio can be induced by the mean-reverting and heteroskedastic features of the aggregate dividend. Second, risk-neutral option pricing model with either the stochastic volatility or the stochastic interest rate or both can be consistent with return predictability. Third, models with either perfect predictability or no predictability will significantly overprice long-term options across different strike prices when the return of the underlying asset exhibits modest predictability. Such large overpricing suggests that return predictability should be properly incorporated into longterm option prices. Fourth, the numerical analysis indicates that stochastic volatility does not affect option prices in a significant way when asset return predictability is properly reflected in the actual stock price process. Fifth, when return predictability is correctly specified, the stochastic interest rate affects the option prices in a very complicated way. For example, when return predictability is correctly specified, a constant-interest-rate-stochastic-volatility model would underprice the longterm options while overpricing in-the-money short-term options. 


\section{Footnotes}

1. For evidence on return predictability, see Bekaert and Hodrick (1992), Breen, Glosten and Jagannathan (1989), Campbell and Hamao (1992), Fama and French (1988a), (1988b) and Ferson and Harvey (1991). For evidence on stochastic volatility, see Rosenberg (1972) and Wiggins (1987).

2. The risk-neutral measure (or the equivalent martingale measure) is not empirically observed. To implement an option pricing model derived under the risk-neutral approach (such as the BS model), one way is to infer the equivalent martingale measure from the actual stock price movement, which is what Lo and Wang did. To do so, one must know (or make assumptions on) the actual probability distribution of the underlying asset price. Furthermore, one needs to know the precise relationship between the two probability measures in order to correctly infer the equivalent probability measure from the actual probability distribution.

3. All expectations in this paper are taken with respect to the filtration specified earlier, unless otherwise specified. The budget constraint is similar to that defined in Duffie (1992) for the security market equilibrium. This Euler equation approach has been adopted by Naik and Lee (1990).

4. The instantaneous volatility of the market portfolio is $\sqrt{V_{t}}$. For presentational simplicity, I choose to discuss the instantaneous variance. The two concepts are equivalent.

5. In an endowment economy, equilibrium risk-free rates generally depend on agents' risk preferences and parameters underlying the dynamics of aggregate dividends (see Lucas 1978, Bailey and Stulz 1989). However, the particular instantaneous risk-free rate obtained here is specific to the current set-up.

6. It is straightforward to show that the market price of risk, $\sqrt{V_{t}}$, satisfies the Novikov condition $E\left[\exp \left(\frac{1}{2} \int_{0}^{\infty}\left\|\sqrt{V_{s}}\right\|^{2} \mathrm{~d} s\right)\right]<\infty$ (see Karatzas and Shreve, 1998). This, in turn, ensures the uniqueness of the equivalent martingale measure.

7. In a similar spirit, Broadie, Detemple, Ghysels and Torres (2000) extensively discussed the joint restrictions on the equilibrium drift and volatility of the stock prices and the equilibrium interest rate. 
8. This is discussed in Appendix C.

9. Bailey and Stulz (1989) obtain a similar result in the absence of return predictability. They find that option prices are influenced by parameters underlying the economic fundamentals through the endogenous volatility function and the risk-free rate in equilibrium. Evidently, the influence of the drift of aggregate dividends on risk-free rates and hence on option prices is only true for the market portfolio. This argument may not be applied to individual stocks.

10. The returns of S\&P 500 in this sample period showed relatively less mean-reverting. The reason that I chose this period is to illustrate the significance of a moderate predictability on option prices. The effect of return predictability could be more pronounced for other periods, especially for the most recent years.

11. For further discussions and references on this negative correlations, see Das and Sundaram (1999).

12. This modified approach is equivalent to using Merton's (1973) extension of the Black-Scholes model. For further discussion on this modification, see Chapter 16 in Hull (2005).

13. Precise formulas for delta hedging ratios are provided in Appendix E.

14. This result is true for European-style options. It is possible that models generating similar prices for European options may not necessarily produce similar prices for American-style options or exotic options. 


\section{References}

[1] Amin, K. I. and Ng, V. K. (1993) Option Valuation with Systematic Stochastic Volatility, Journal of Finance, 48, No. 3, 881-910.

[2] Bailey, W. and Stulz, R. (1989) The Pricing of Stock Index Options in a General Equilibrium Model, Journal of Financial and Quantitative Analysis, 24, 1-12.

[3] Bakshi, G. and Chen, Z. (1997) An Alternative Valuation Model for Contingent Claims, Journal of Financial Economics, 44, 123-165.

[4] Bekaert, G. and Hodrick, R. (1992) Characterizing Predictable Components in Excess Returns on Equity and Foreign Exchange Markets, Journal of Finance, 47, 467-509.

[5] Black, F. and Scholes, M. (1973) The Pricing of Options and Corporate Liabilities, Journal of Political Economy, 81, 637-655.

[6] Breen, W., Glosten, L. and Jagannathan, R. (1989) Economic Significance of Predictable Variations in Stock Index Returns, Journal of Finance, 44, 1177-1189.

[7] Broadie, M., Detemple, J. B., Ghysels, E. and Torres, O. (2000) American Options with Stochastic Dividends and Volatility: a Nonparameteric Investigation, Journal of Econometrics, vol. $94,53-92$.

[8] Campbell, J. and Hamao, Y. (1992) Predictable Stock Returns in the United States and Japan: A Study of Long-term Capital Market Integration, Journal of Finance, 47, 43-70.

[9] Cox, C. J. (1996) The Constant Elasticity of Variance Option Pricing Model, Journal of Portfolio Management, special issues, 15-17.

[10] Cox, C. J., Ingersoll, J. and Ross, S. A. (1985a) An Intertemporal General Equilibrium Model of Asset Price, Econometrica, 53, No. 2, 363-384.

[11] Cox, C. J., Ingersoll, J. and Ross, S. A. (1985b) A Theory of the Term Structure of Interest Rates, Econometrica, 53, No. 2, 384-407. 
[12] Das, S. and Sundaram, R. K. (1999) Of Smiles and Smirks: A Term Structure Perspective, Journal of Financial Quantitative Analysis, 34, 211-239.

[13] Dupire, B., 1994, Pricing with a Smile, Risk, 7, No.1, 18-20.

[14] Duffie, D., 1992, Dynamic Asset Pricing Theory, Princeton: Princeton University Press.

[15] Fama, E. and French, K. R. (1988a) Permanent and Temporary Components of Stock Market Prices, Journal of Political Economy, 96, No. 1-3, 246-273.

[16] Fama, E. and French, K. R. (1988b) Dividend Yields and Expected Stock Returns, Journal of Financial Economics, 22, 3-26.

[17] Ferson, W. and Harvey, C. (1991) Sources of Predictability in Portfolio Returns, Financial Analysts Journal May-June, 49-56.

[18] Feller, W. (1951) Two Singular Diffusion Problems, Annals of Mathematics, 54, 173-182.

[19] Heston, S. (1993) A Closed-Form Solution for Options with Stochastic Volatility with Applications to Bond and Currency Options, Review of Financial Studies, 6, 327-343.

[20] Harrison, M. and Kreps, D. (1979) Martingale and Multiperiod Securities Markets, Journal of Economic Theory, 20, 381-408.

[21] Hobson, D. G. and Rogers, L. C. G. (1998) Complete Models with Stochastic Volatility, Mathematical Finance, 8, 27-48.

[22] Hull, J. (2005) Options, Futures and other Derivative Securities, sixth edition, New Jersey: Prentice Hall.

[23] Hull, J. and White, A. (1987) The Pricing of Options on Assets with Stochastic Volatilities, Journal of Finance, 42, 281-300.

[24] Johnson, N. and Kotz, S. (1970) Continuous Univariate Distributions, New York: Houghton Mifflin.

[25] Karatzas, I. and Shreve, S. E. (1988) Brownian Motion and Stochastic Calculus, New York: Springer - Verlag. 
[26] Lo, A. W. and Wang, J. (1995) Implementing Option Pricing Models When Asset Returns Are Predictable, Journal of Finance, 50, No.1, 87 - 129.

[27] Lucas, R. E. (1978) Asset Prices in an Exchange Economy, Econometrica, 46, 1429-1445.

[28] Marsh, T. A. and Merton, R. (1987) Dividend Behavior for the Aggregate Stock Market, Journal of Business, 60, 1-40.

[29] Merton, R. (1971) Optimum Consumption Rules in a Continuous-Time Model, Journal of Economic Theory, 3, $373-413$.

[30] Merton, R. (1976) Option Pricing when Underlying Stock Returns are Discontinuous, Journal of Financial Economics, 3, 125-144.

[31] Naik, V. and Lee, M. (1990) General Equilibrium Pricing of Options on the Market Portfolio with Discontinuous Returns, Review of Financial Studies, 3, No.4, 493-521.

[32] Oldfield, G., Rogalski, R. and Jarrow, R. (1977) An Auto Regressive Jump Process for Common Stock Returns, Journal of Financial Economics, 5, 389-418.

[33] Rosenberg, B. (1972) The Behavior of Random Variables with Non Stationary Variance and the Distribution of Security Prices, Research Program in Finance working paper no.11, University of California.

[34] Stein, E. M. and Stein, J. C. (1991) Stock Price Distributions with Stochastic Volatility: An Analytic Approach, Review of Financial Studies, 4, No. 4, 727-752.

[35] Vasicek, O. (1977) An Equilibrium Characterization of the Term Structure, Journal of Financial Economics, 5, 177-188.

[36] Wiggins, J. B. (1987) Option Values under Stochastic Volatility: Theory and Empirical Estimates, Journal of Financial Economics, 19, 351 - 372. 


\section{Appendices}

\section{A. Proofs of Proposition 1.1}

\section{A.1. The Price of the Risky Stock}

Proof. Since the volatility process in (1.6) resembles the single state variable in Cox-Ingersoll-Ross (1985b), it satisfies all the properties identified by Cox-Ingersoll-Ross (1985b, page 391): (i) $V_{t}$ is strictly positive if $a_{1}+0.5 a_{2}>0$ and $\left(2 a_{1}+a_{2}\right) \xi \geq a_{2}^{2}$; (ii) $V_{T}$ conditional on $\left(V_{t}, t\right)$ has a non-central $\chi^{2}$ distribution with the following density function: ${ }^{1}$

where

$$
f\left(V_{T}, T ; V_{t}, t\right)=\alpha(t, T) e^{-(x+\lambda)} \sum_{j=0}^{\infty} \frac{(x \lambda)^{j}}{\Gamma(v+j) j !}
$$

$$
\lambda \equiv \alpha(t, T) V_{t} e^{-\left(a_{1}+\frac{1}{2} a_{2}\right)(T-t)}, \quad x \equiv \alpha(t, T) V_{T},
$$

and $\alpha(t, T)$ is specified in Proposition 2.1. The Euler equation (2.3) implies the following price for the market portfolio at time $t$

$$
S_{t}\left(\delta_{t}\right)=e^{\rho t} \delta_{t} E_{t}\left(\int_{t}^{\infty} e^{-\rho T} \frac{1}{\delta_{T}} \times \delta_{T} \mathrm{~d} T\right)=\frac{\delta_{t}}{\rho}, \quad \forall \quad t \in(0, \infty)
$$

Since the stock price is linear in $\delta$, the dynamics of the stock price are

$$
\begin{array}{rlrl}
\frac{\mathrm{d} S}{S} & =\left(\mu_{t}-\rho\right) \mathrm{d} t+\sqrt{V_{t}} \mathrm{~d} z_{t} & \text { with } \\
\mu_{t} & =\rho+b_{1}-a_{1}\left(\ln \delta_{t}-u t\right) & \text { and } & V_{t}=b_{2}+a_{2}\left(\ln \delta_{t}-u t\right) .
\end{array}
$$

\section{A.2. The Instantaneous Risk-free Rate and the Yield-to-Maturity}

Proof. I first calculate the pure discount price with maturity $T$ at time $t \leq T$. From the Euler equation (2.3), I have

$$
B_{t}(T)=e^{\rho t} \delta_{t} E_{t}\left(e^{-\rho T} \frac{1}{\delta_{T}} \times 1\right)=e^{-\rho(T-t)} \delta_{t} E_{t}\left(\frac{1}{\delta_{T}}\right), \quad \forall \quad t \in(0, T) .
$$

\footnotetext{
${ }^{1}$ See Johnson and Kotz (1970) for the non-central $\chi^{2}$ distribution and Feller (1951) for the corresponding probability transition function.
} 
The price of a pure discount bond can be computed based on the conditional density in (A.1):

$$
\begin{aligned}
B_{t}(T) & =e^{-\rho(T-t)} e^{\frac{-b_{2}+V_{t}}{a_{2}}+u t} \int_{0}^{\infty} e^{\frac{b_{2}-V_{T}}{a_{2}}-u T} \alpha(t, T) e^{-(x+\lambda)} x^{v-1} \sum_{j=0}^{\infty} \frac{(x \lambda)^{j}}{j ! \Gamma(v+j)} \mathrm{d} V_{T} \\
& =e^{-(\rho+u)(T-t)+\frac{V_{t}}{a_{2}}} \sum_{j=0}^{\infty} \frac{e^{-\lambda} \lambda^{j}}{j ! \Gamma(v+j)} \Gamma(v+j)\left(\frac{\alpha(t, T) a_{2}}{\alpha(t, T) a_{2}+1}\right)^{v+j} \\
& =\left(\frac{\alpha(t, T) a_{2}}{\alpha(t, T) a_{2}+1}\right)^{v} e^{-\left(\rho+u-\frac{2\left(a_{1}+a_{2}\right) A(t, T) V_{t}}{a_{2}^{3} \alpha(t, T)(T-t)}\right)(T-t)} .
\end{aligned}
$$

The yield-to-maturity, $R(t, T)$, is defined through $e^{-R(t, T)(T-t)} \equiv B_{t}(T)$. Therefore,

$$
R(t, T)=\rho+u-v \frac{\ln (A(t, T))}{T-t}-\left[b_{2}+a_{2}\left(\ln \delta_{t}-u t\right)\right] A(t, T)\left(\frac{a_{1}}{a_{2}}+1\right) \frac{1-e^{-\left(a_{1}+a_{2} / 2\right)(T-t)}}{\left(a_{1}+a_{2} / 2\right)(T-t)} .
$$

Then, the spot instantaneous interest rate $r_{t}$ is

$$
r_{t}=\lim _{T \rightarrow t} R(t, T)=\rho+u+\frac{v}{a_{2}}-\left(\frac{a_{1}}{a_{2}}+1\right)\left[b_{2}+a_{2}\left(\ln \delta_{t}-u t\right)\right] .
$$

\section{B. Proof of Proposition 3.1:}

\section{B.1. Stock Option Valuation under $a_{2}>0$}

Under $a_{2}>0, S_{T} \geq K$ implies $V_{T} \geq d(K)=V_{t}-a_{2}\left[\ln S_{t} / K+u(T-t)\right]$. Thus

$$
\begin{aligned}
C_{t}\left(S_{t}, K, T\right) & =e_{t}^{-\rho(T-t)} \delta_{t} E_{t}\left(\frac{1}{\delta_{T}} \times \max \left(S_{T}-K, 0\right)\right) \\
& =e^{-\rho(T-t)} S_{t} \operatorname{Prob}\left[V_{T} \geq d(K)\right]-e^{-\rho(T-t)} K \delta_{t} \int_{d(K)}^{\infty} \frac{1}{\delta_{T}} f\left(V_{T} \mid V_{t}\right) \mathrm{d} V_{T} .
\end{aligned}
$$

Then,

$$
\begin{gathered}
e^{-\rho(T-t)} S_{t} \operatorname{Prob}\left[V_{T} \geq d(K)\right]=e^{-\rho(T-t)} S_{t} \int_{d(K)}^{\infty} \alpha(t, T) e^{-(x+\lambda)} x^{v-1} \sum_{j=0}^{\infty} \frac{(x \lambda)^{j}}{j ! \Gamma(v+j)} \mathrm{d} V_{T} \\
=e^{-\rho(T-t)} S_{t} \sum_{j=0}^{\infty} \frac{e^{-\lambda} \lambda^{j}}{j !} \frac{\Gamma(v+j, \alpha(t, T) d(K))}{\Gamma(v+j)}=e^{-\rho(T-t)} S_{t} \chi_{1},
\end{gathered}
$$

and

$$
\begin{aligned}
& e^{-\rho(T-t)} K \delta_{t} \int_{d(K)}^{\infty} \frac{1}{\delta_{T}} f\left(V_{T} \mid V_{t}\right) \mathrm{d} V_{T} \\
& \quad=K e^{-\rho(T-t)+\frac{-b_{2}+V_{t}}{a_{2}}+u t} \int_{d(K)}^{\infty} e^{\frac{b_{2}-V_{T}}{a_{2}}-u T} \alpha(t, T) e^{-(x+\lambda)} x^{v-1} \sum_{j=0}^{\infty} \frac{(x \lambda)^{j}}{j ! \Gamma(v+j)} \mathrm{d} V_{T}
\end{aligned}
$$




$$
\begin{aligned}
& =K e^{-(\rho+u)(T-t)+\frac{V_{t}}{a_{2}}} \sum_{j=0}^{\infty} \frac{e^{-\lambda} \lambda^{j}}{j ! \Gamma(v+j)} \int_{d(K)}^{\infty} \alpha(t, T) e^{-\frac{V_{T}}{a_{2}}} e^{-\alpha(t, T) V_{T}}\left(\alpha(t, T) V_{T}\right)^{v+j-1} \mathrm{~d} V_{T} \\
& =K e^{-(\rho+u)(T-t)+\frac{V_{t}}{a_{2}} \sum_{j=0}^{\infty} \frac{e^{-\lambda} \lambda^{j}}{j ! \Gamma(v+j)} \Gamma\left[v+j, \frac{\alpha(t, T)}{A(t, T)} d(K)\right] A(t, T)^{v+j}} \\
& =K e^{-R(t, T)(T-t)} \sum_{j=0}^{\infty} \frac{e^{-A(t, T) \lambda}(A(t, T) \lambda)^{j}}{j !} \frac{\Gamma\left(v+j, \frac{\alpha(t, T)}{A(t, T)} d(K)\right)}{\Gamma(v+j)}=K e^{-R(t, T)(T-t)} \chi_{2} .
\end{aligned}
$$

Therefore,

$$
C_{t}\left(S_{t}, K, T\right)=e^{-\rho(T-t)} S_{t} \chi_{1}-K e^{-R(t, T)(T-t)} \chi_{2} .
$$

\section{B.2. Stock Option Valuation under $a_{2}<0$}

Proof. Under $a_{2}<0, S_{T} \geq K$ implies $V_{T} \leq d(K)=V_{t}-a_{2}\left[\ln S_{t} / K+u(T-t)\right]$. Thus

$$
\begin{aligned}
C_{t}\left(S_{t}, K, T\right) & =e_{t}^{-\rho(T-t)} \delta_{t} E_{t}\left(\frac{1}{\delta_{T}} \times \max \left(S_{T}-K, 0\right)\right) \\
& =e^{-\rho(T-t)} S_{t} \operatorname{Prob}\left[V_{T} \leq d(K)\right]-e^{-\rho(T-t)} K \delta_{t} \int_{0}^{d(K)} \frac{1}{\delta_{T}\left(V_{T}\right)} f\left(V_{T} \mid V_{t}\right) \mathrm{d} V_{T}
\end{aligned}
$$

Tedious algebra shows that

$$
C_{t}\left(S_{t}, K, T\right)=S_{t} e^{-\rho(T-t)}\left(1-\chi_{1}\right)-K e^{-R(t, T)(T-t)}\left(1-\chi_{2}\right) .
$$

\section{B.3. Stock Option Valuation under $a_{2}=0$}

When $a_{2}=0, \ln \delta_{T} \mid \ln \delta_{t}$ has a Gaussian distribution:

$$
\begin{aligned}
& f\left(\ln \delta_{T} \quad \mid \quad \delta_{t}\right)=\frac{1}{\sqrt{2 \pi \Sigma^{2}(T-t)}} \exp \left(-\frac{\left(\ln \delta_{T}-\Psi\right)^{2}}{2 \Sigma^{2}(T-t)}\right) \text { with } \quad \Sigma^{2}=b_{2} \frac{1-e^{-2 a_{1}(T-t)}}{2 a_{1}(T-t)} \\
& \text { and } \quad \Psi=\ln \delta_{t} e^{-a_{1}(T-t)}+u\left(T-t e^{-a_{1}(T-t)}\right)+\frac{b_{1}-u-\frac{1}{2} b_{2}}{a_{1}}\left(1-e^{-a_{1}(T-t)}\right) .
\end{aligned}
$$

European call options under $a_{2}=0$ can be priced as follows:

$$
C_{t}\left(S_{t}, K, T\right)=e_{t}^{-\rho(T-t)} \delta_{t} E_{t}\left(\frac{1}{\delta_{T}} \times \max \left(S_{T}-K, 0\right)\right)
$$

It can be easily shown that

$$
C_{t}\left(S_{t}, K, T\right)=e^{-\rho(T-t)} S_{t} N\left(d_{1}\right)-e^{-\bar{R}(t, T)(T-t)} K N\left(d_{2}\right)
$$


where

$$
\begin{aligned}
& d_{1}=\frac{\ln S_{t} / K+\left(\bar{R}(t, T)-\rho+\frac{1}{2} \Sigma^{2}\right)(T-t)}{\Sigma \sqrt{T-t}} \quad \text { and } \quad d_{2}=d_{1}-\Sigma \sqrt{T-t} \\
& \bar{R}(t, T)=\lim _{a_{2} \rightarrow 0} R(t, T) \\
& =\rho+u+\left(b_{1}-u-\frac{1}{2} b_{2}-a_{1}\left(\ln \delta_{t}-u t\right)\right) \frac{1-e^{-a_{1}(T-t)}}{a_{1}(T-t)}-\frac{b_{2}}{2} \frac{1-e^{-2 a_{1}(T-t)}}{2 a_{1}(T-t)} .
\end{aligned}
$$

\section{The Partial Differential Equation Approach}

Based on Assumption 2 for the de-trended log aggregate dividend, the process for aggregate dividend can be written as

$$
\begin{gathered}
\frac{\mathrm{d} \delta}{\delta}=\mu_{\delta} \mathrm{d} t+\sigma_{\delta} \mathrm{d} z_{t} \quad \text { with } \\
\mu_{\delta}=\left(b_{1}-a_{1}\left(\ln \delta_{t}-u t\right)\right) \quad \text { and } \quad \sigma_{\delta}=\sqrt{b_{2}+a_{2}\left(\ln \delta_{t}-u t\right)}
\end{gathered}
$$

Denote the process for the price of asset $i, X_{i}$, as

$$
\begin{gathered}
\frac{\mathrm{d} X^{i}}{X^{i}}=\left(\mu^{i}-\frac{q^{i}}{X^{i}}\right) \mathrm{d} t+\sigma^{i} \mathrm{~d} z \quad \text { with } \\
\mu^{i} X^{i}=\frac{\partial X^{i}}{\partial \delta} \mu_{\delta} \delta+\frac{\partial X^{i}}{\partial t}+\frac{1}{2} \frac{\partial^{2} X^{i}}{\partial \delta^{2}} \sigma_{\delta}^{2} \delta^{2}+q^{i} \quad \text { and } \sigma^{i} X^{i}=\frac{\partial X^{i}}{\partial \delta} \sigma_{\delta} \delta .
\end{gathered}
$$

The price processes of for all assets are determined in equilibrium.

Define the total wealth as $W=\sum_{i=0}^{N} \theta^{i} X^{i}$ and the percentage wealth invested in asset $i$ as $w^{i}=\frac{\theta^{i} X^{i}}{W}$. Then, $\sum_{i=0}^{N} w^{i}=1$. For simplicity, assume the pure discount bond is asset 0 . Therefore,

$$
w^{0}=1-\sum_{i=1}^{N} w^{i} \quad \text { and } \quad \frac{\mathrm{d} B}{B}=r \mathrm{~d} t .
$$

The budget constraint below is similar to that in Merton (1971)

$$
\begin{aligned}
& \frac{\mathrm{d} W}{W}=\mu_{W} \mathrm{~d} t+\sigma_{W} \mathrm{~d} z_{t} \quad \text { with } \\
& \mu_{W}=\left(r+\sum_{i=1}^{N} w^{i}\left(\mu^{i}-r\right)-\frac{c}{W}\right) \quad \text { and } \quad \sigma_{W}=\left(\sum_{i=1}^{N} w^{i} \sigma^{i}\right) .
\end{aligned}
$$

Denote

$$
J(W, \delta, t)=\max _{w, c} E_{t}\left(\int_{t}^{\infty} U\left(c_{\tau}, \tau\right) \mathrm{d} \tau\right) \quad \text { and } \quad \Psi(w, c ; W, \delta, t)=U\left(c_{t}, t\right)+\mathfrak{L}[J]
$$


where $\mathfrak{L}[J]$ is the differential generator of $J$ associated with its control

$$
\mathfrak{L}[J]=J_{t}+J_{W} W \mu_{W}+J_{\delta} \delta \mu_{\delta}+J_{W \delta} \delta \sigma_{\delta} W \sigma_{W}+\frac{1}{2} J_{W W} W^{2} \sigma_{W}^{2}+\frac{1}{2} J_{\delta \delta} \delta^{2} \sigma_{\delta}^{2}
$$

The agent solves $w, c$ by maximizing $\Psi(w, c ; W, \delta, t)$. The first order conditions are:

$$
\begin{aligned}
& \frac{\partial \Psi}{\partial c}=U_{c}-J_{W}=0 \\
& \frac{\partial \Psi}{\partial w^{i}}=J_{W} W\left(\mu^{i}-r\right)+J_{W \delta} \delta \sigma_{\delta} W \sigma^{i}+J_{W W} W^{2} \sigma_{W} \sigma^{i}=0 \quad \forall \quad i=1,2, \ldots, N .
\end{aligned}
$$

Thus, the Partial Differential Equation (PDE) satisfied by the price of asset $i$ is derived from the first order conditions as

$$
\frac{\partial X^{i}}{\partial \delta} \mu_{\delta} \delta+\frac{\partial X^{i}}{\partial t}+\frac{1}{2} \frac{\partial^{2} X^{i}}{\partial \delta^{2}} \sigma_{\delta}^{2} \delta^{2}+q^{i}+\frac{J_{W \delta}}{J_{W}} \frac{\partial X^{i}}{\partial \delta} \delta^{2} \sigma_{\delta}^{2}+\frac{W J_{W W}}{J_{W}} \frac{\partial X^{i}}{\partial \delta} \sigma_{W} \sigma_{\delta} \delta=r X^{i}
$$

Since the period utility is $U\left(c_{t}, t\right)=e^{-\rho t} \ln c_{t}$, then $\frac{J_{W \delta}}{J_{W}}=0$ and $\frac{W J_{W W}}{J_{W}}=-1$ (see Merton 1971 ). Then the PDE is further reduced to

$$
\frac{\partial X^{i}}{\partial \delta} \mu_{\delta} \delta+\frac{\partial X^{i}}{\partial t}+\frac{1}{2} \frac{\partial^{2} X^{i}}{\partial \delta^{2}} \sigma_{\delta}^{2} \delta^{2}+q^{i}-\frac{\partial X^{i}}{\partial \delta} \sigma_{W} \sigma_{\delta} \delta=r X^{i}
$$

Applying Lemma 4 of Cox-Ingersoll-Ross (1985a, p. 380) to the above PDE, one can obtain the same solution as that of the Euler equation.

\section{Conditional Expected Stock Price}

The conditional expectation of the price for the market portfolio is computed based on the conditional density in (A.1):

$$
\begin{aligned}
E_{t}\left(S_{T}\right) & =E_{t}\left(\frac{\delta_{T}}{\rho}\right)=\frac{1}{\rho} \int_{0}^{\infty} e^{\frac{-b_{2}+V_{T}}{a_{2}}+u T} \alpha(t, T) e^{-(x+\lambda)} x^{v-1} \sum_{j=0}^{\infty} \frac{(x \lambda)^{j}}{j ! \Gamma(v+j)} \mathrm{d} V_{T} \\
& =\frac{e^{\frac{-b_{2}}{a_{2}}+u T}}{\rho} \sum_{j=0}^{\infty} \frac{e^{-\lambda} \lambda^{j}}{j ! \Gamma(v+j)} \Gamma(v+j)\left(\frac{\alpha(t, T) a_{2}}{\alpha(t, T) a_{2}-1}\right)^{v+j} \\
& =S_{t} \exp \left(u(T-t)-V_{t} \frac{a_{1}\left(1-e^{-\left(a_{1}+a_{2} / 2\right)(T-t)}\right)}{a_{2}\left(a_{1}+a_{2} / 2\right)}\right)\left(\frac{\alpha(t, T) a_{2}}{\alpha(t, T) a_{2}-1}\right)^{v} .
\end{aligned}
$$




\section{E. Delta Ratios for Call and Put Options}

For $a_{2}>0$,

$$
\begin{aligned}
& \Delta_{\text {call }}=\frac{\partial C_{t}}{\partial S_{t}}=\frac{C_{t}}{S_{t}}+\frac{K}{S_{t}} A(t, T) e^{-\left[a_{1}+\frac{1}{2} a_{2}+R(t, T)\right](T-t)} \sum_{j=0}^{\infty} \frac{e^{-\alpha \lambda}(A \lambda)^{j}}{j !} \frac{\Gamma\left(v+j+1, \frac{\alpha(t, T)}{A(t, T)} d(K)\right)}{\Gamma(v+j+1)} \\
& \Delta_{\text {put }}=\frac{\partial P_{t}}{\partial S_{t}}=\frac{\partial C_{t}}{\partial S_{t}}+\frac{K}{S_{t}} e^{-R(t, T)(T-t)}\left(1-A(t, T) e^{-\left(a_{1}+\frac{1}{2} a_{2}\right)(T-t)}\right)-e^{-\rho(T-t)} .
\end{aligned}
$$

For $a_{2}<0$,

$$
\begin{aligned}
& \Delta_{\text {call }}=\frac{\partial C_{t}}{\partial S_{t}}=\frac{C_{t}}{S_{t}}+\frac{K}{S_{t}} A(t, T) e^{-\left[\left(a_{1}+\frac{1}{2} a_{2}\right)+R(t, T)\right](T-t)} \sum_{j=0}^{\infty} \frac{e^{-\alpha \lambda}(A \lambda)^{j}}{j !} \frac{\gamma\left(v+j+1, \frac{\alpha(t, T)}{A(t, T)} d(K)\right)}{\Gamma(v+j+1)} \\
& \Delta_{\text {put }}=\frac{\partial P_{t}}{\partial S_{t}}=\frac{\partial C_{t}}{\partial S_{t}}+\frac{K}{S_{t}} e^{-R(t, T)(T-t)}\left(1-A(t, T) e^{-\left(a_{1}+\frac{1}{2} a_{2}\right)(T-t)}\right)-e^{-\rho(T-t)} .
\end{aligned}
$$

For $a_{2}=0$,

$$
\begin{aligned}
& \Delta_{\text {call }}=\frac{\partial C_{t}}{\partial S_{t}}=\frac{C_{t}}{S_{t}}+\frac{K}{S_{t}} e^{-\left[a_{1}+R(t, T)\right](T-t)} N\left(d_{2}\right) \\
& \Delta_{\text {put }}=\frac{\partial P_{t}}{\partial S_{t}}=\frac{\partial C_{t}}{\partial S_{t}}+\frac{K}{S_{t}} e^{-R(t, T)(T-t)}\left(1-e^{-a_{1}(T-t)}\right)-e^{-\rho(T-t)} .
\end{aligned}
$$


Table 3: Estimation Results

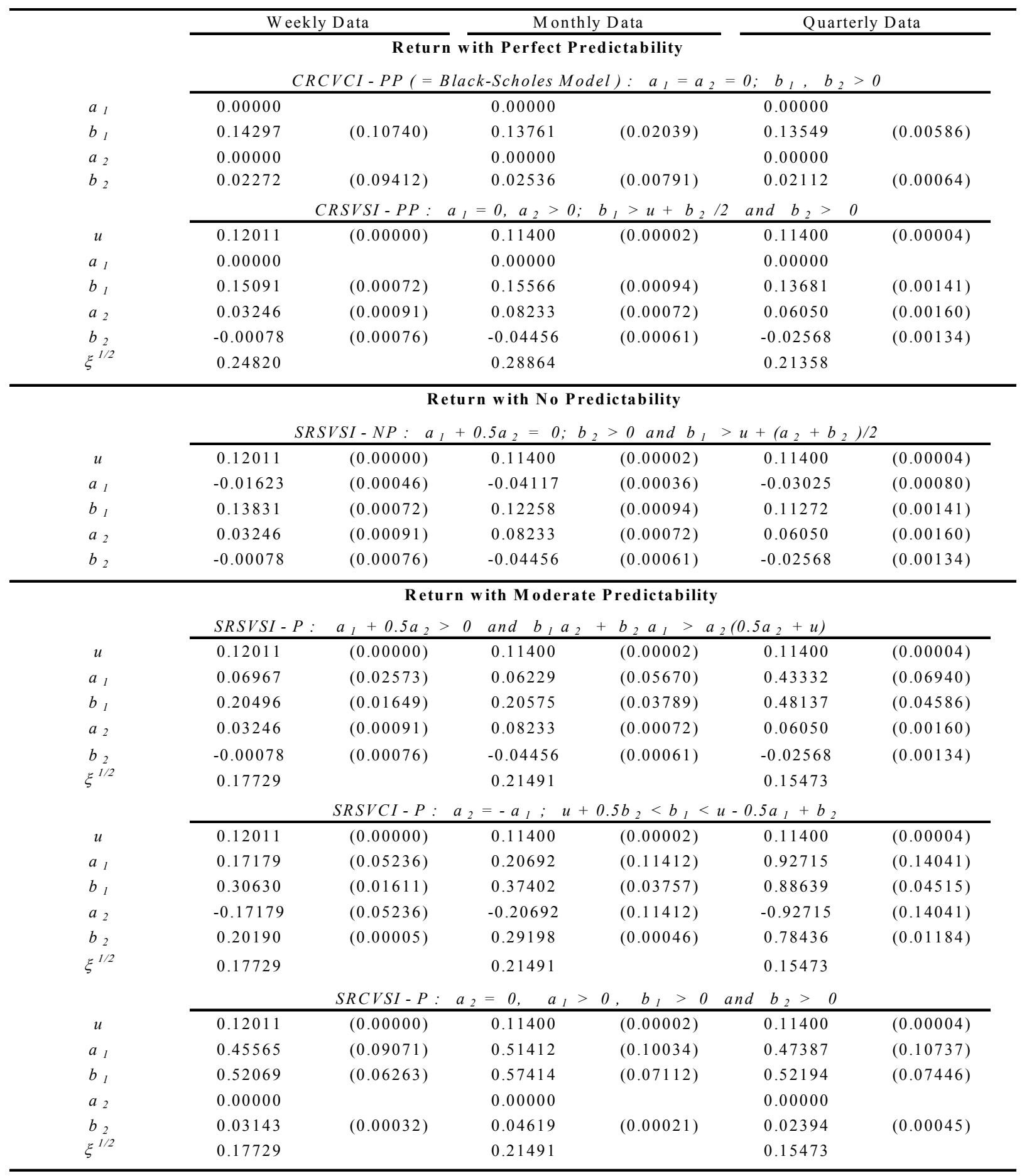

Note: $\quad 1 . \xi=\left[a_{1} b_{2}+a_{2}\left(b_{1}-u\right)\right] /\left(a_{1}+0.5 a_{2}\right)$ is the long-run mean of variance.

2. Parameters are annualized. 3. Numbers in parentheses are estimation errors. 
Table 4: Call Option Prices under Different Predictability

With Stochastic Volatility and Stochastic Interest Rate

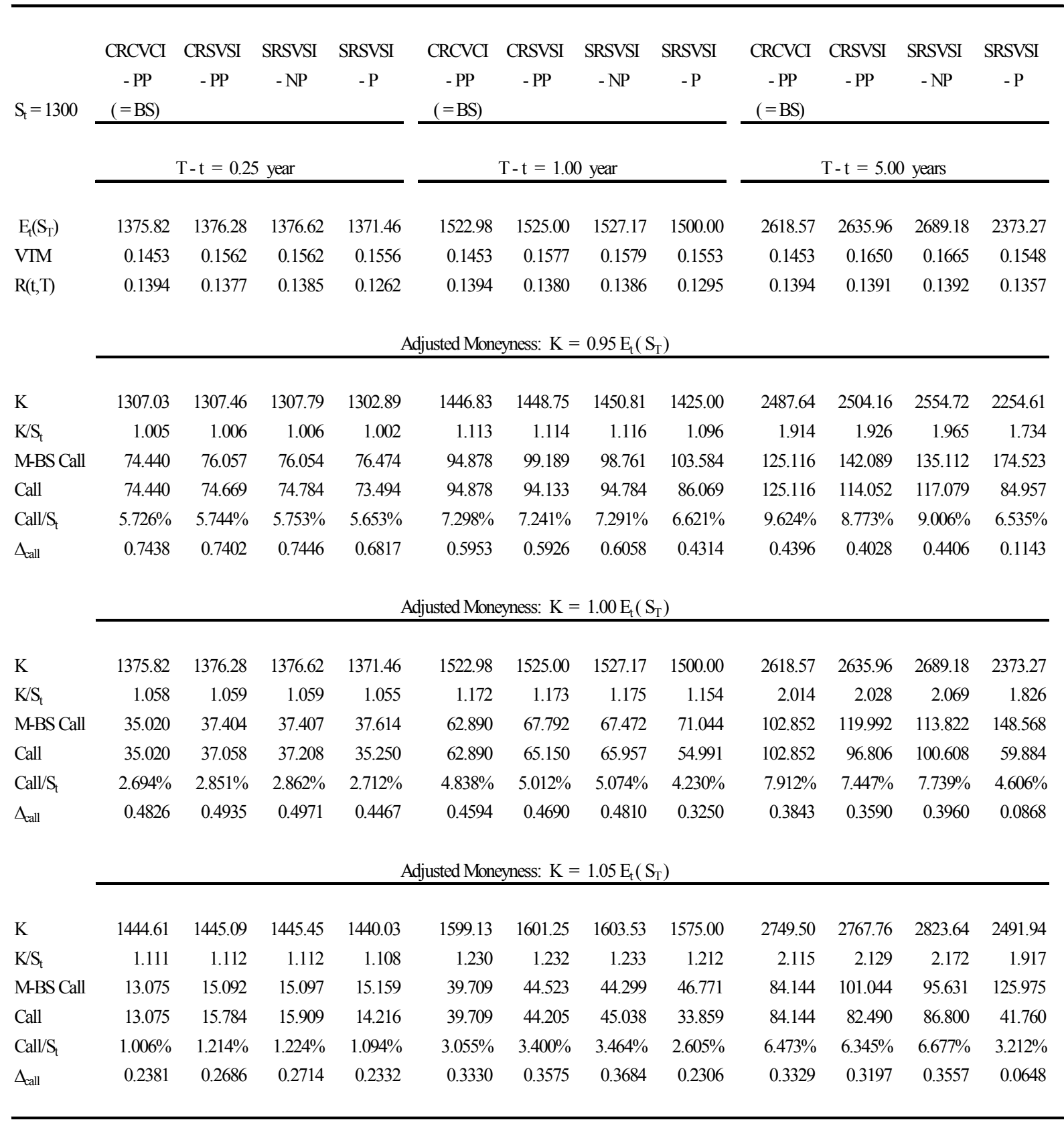

Note: 1. All Parameters used in this table are estimated with quarterly data.

2. BS and M-BS stand for Black-Scholes and modified-Black-Scholes, respectively. 
Table 5: Put Option Prices under Different Predictability with Stochastic Volatility and Stochastic Interest Rate

\begin{tabular}{|c|c|c|c|c|c|c|c|c|c|c|c|c|}
\hline \multirow[t]{2}{*}{$S_{t}=1300$} & $\begin{array}{c}\text { CRCVCI } \\
-\mathrm{PP} \\
(=\mathrm{BS}) \\
\end{array}$ & $\begin{array}{c}\text { CRSVSI } \\
\text { - PP }\end{array}$ & $\begin{array}{l}\text { SRSVSI } \\
\text { - NP }\end{array}$ & $\begin{array}{c}\text { SRSVSI } \\
-\mathrm{P}\end{array}$ & $\begin{array}{c}\text { CRCVCI } \\
-\mathrm{PP} \\
(=\mathrm{BS}) \\
\end{array}$ & $\begin{array}{c}\text { CRSVSI } \\
\text { - PP }\end{array}$ & $\begin{array}{c}\text { SRSVSI } \\
\text { - NP }\end{array}$ & $\begin{array}{c}\text { SRSVSI } \\
\text { - } \mathrm{P}\end{array}$ & $\begin{array}{c}\text { CRCVCI } \\
\text { - PP } \\
(=\mathrm{BS}) \\
\end{array}$ & $\begin{array}{c}\text { CRSVSI } \\
\text { - PP }\end{array}$ & $\begin{array}{l}\text { SRSVSI } \\
-\mathrm{NP}\end{array}$ & $\begin{array}{l}\text { SRSVSI } \\
-\mathrm{P}\end{array}$ \\
\hline & \multicolumn{4}{|c|}{$\mathrm{T}-\mathrm{t}=0.25$ year } & \multicolumn{4}{|c|}{$\mathrm{T}-\mathrm{t}=1.00$ year } & \multicolumn{4}{|c|}{$\mathrm{T}-\mathrm{t}=5.00$ years } \\
\hline $\mathrm{E}_{\mathrm{t}}\left(\mathrm{S}_{\mathrm{T}}\right)$ & 1375.82 & 1376.28 & 1376.62 & 1371.46 & 1522.98 & 1525.00 & 1527.17 & 1500.00 & 2618.57 & 2635.96 & 2689.18 & 2373.27 \\
\hline VTM & 0.1453 & 0.1562 & 0.1562 & 0.1556 & 0.1453 & 0.1577 & 0.1579 & 0.1553 & 0.1453 & 0.1650 & 0.1665 & 0.1548 \\
\hline $\mathrm{R}(\mathrm{t}, \mathrm{T})$ & 0.1394 & 0.1377 & 0.1385 & 0.1262 & 0.1394 & 0.1380 & 0.1386 & 0.1295 & 0.1394 & 0.1391 & 0.1392 & 0.1357 \\
\hline \multicolumn{13}{|c|}{ Adjusted Moneyness: $\mathrm{K}=0.95 \mathrm{E}_{\mathrm{t}}\left(\mathrm{S}_{\mathrm{T}}\right)$} \\
\hline K & 1307.03 & 1307.46 & 1307.79 & 1302.89 & 1446.83 & 1448.75 & 1450.81 & 1425.00 & 2487.64 & 2504.16 & 2554.72 & 2254.61 \\
\hline $\mathrm{K} / \mathrm{S}_{\mathrm{t}}$ & 1.005 & 1.006 & 1.006 & 1.002 & 1.113 & 1.114 & 1.116 & 1.096 & 1.914 & 1.926 & 1.965 & 1.734 \\
\hline M-BS Put & 14.982 & 17.590 & 17.605 & 17.227 & 56.340 & 64.072 & 64.625 & 58.303 & 190.633 & 217.566 & 234.834 & 144.854 \\
\hline Put & 14.982 & 16.201 & 16.335 & 14.247 & 56.340 & 59.017 & 60.647 & 40.788 & 190.633 & 189.528 & 216.801 & 55.289 \\
\hline $\mathrm{Put} / \mathrm{S}_{\mathrm{t}}$ & $1.152 \%$ & $1.246 \%$ & $1.257 \%$ & $1.096 \%$ & $4.334 \%$ & $4.540 \%$ & $4.665 \%$ & $3.138 \%$ & $14.664 \%$ & $14.579 \%$ & $16.677 \%$ & $4.253 \%$ \\
\hline$\Delta_{\text {put }}$ & -0.2499 & -0.2394 & -0.2420 & -0.2022 & -0.3800 & -0.3278 & -0.3416 & -0.1807 & -0.4429 & -0.2485 & -0.3161 & -0.1196 \\
\hline \multicolumn{13}{|c|}{ Adjusted Moneyness: $\mathrm{K}=1.00 \mathrm{E}_{\mathrm{t}}\left(\mathrm{S}_{\mathrm{T}}\right)$} \\
\hline K & 1375.82 & 1376.28 & 1376.62 & 1371.46 & 1522.98 & 1525.00 & 1527.17 & 1500.00 & 2618.57 & 2635.96 & 2689.18 & 2373.27 \\
\hline $\mathrm{K} / \mathrm{S}_{\mathrm{t}}$ & 1.058 & 1.059 & 1.059 & 1.055 & 1.172 & 1.173 & 1.175 & 1.154 & 2.014 & 2.028 & 2.069 & 1.826 \\
\hline M-BS Put & 41.996 & 45.423 & 45.445 & 44.813 & 90.595 & 99.099 & 99.810 & 91.651 & 233.592 & 261.216 & 280.567 & 179.112 \\
\hline Put & 41.996 & 45.077 & 45.247 & 42.449 & 90.595 & 96.458 & 98.295 & 75.598 & 233.592 & 238.030 & 267.354 & 90.429 \\
\hline $\mathrm{Put} / \mathrm{S}_{\mathrm{t}}$ & $3.230 \%$ & $3.467 \%$ & $3.481 \%$ & $3.265 \%$ & $6.969 \%$ & $7.420 \%$ & $7.561 \%$ & $5.815 \%$ & $17.969 \%$ & $18.310 \%$ & $20.566 \%$ & $6.956 \%$ \\
\hline$\Delta_{\text {put }}$ & -0.5112 & -0.4853 & -0.4891 & -0.4314 & -0.5159 & -0.4485 & -0.4650 & -0.2680 & -0.4982 & -0.2801 & -0.3541 & -0.2150 \\
\hline \multicolumn{13}{|c|}{ Adjusted Moneyness: $\mathrm{K}=1.05 \mathrm{E}_{\mathrm{t}}\left(\mathrm{S}_{\mathrm{T}}\right)$} \\
\hline K & 1444.61 & 1445.09 & 1445.45 & 1440.03 & 1599.13 & 1601.25 & 1603.53 & 1575.00 & 2749.50 & 2767.76 & 2823.64 & 2491.94 \\
\hline $\mathrm{K} / \mathrm{S}_{\mathrm{t}}$ & 1.111 & 1.112 & 1.112 & 1.108 & 1.230 & 1.232 & 1.233 & 1.212 & 2.115 & 2.129 & 2.172 & 1.917 \\
\hline M-BS Put & 86.485 & 89.598 & 89.623 & 88.804 & 133.657 & 142.254 & 143.113 & 133.267 & 280.107 & 308.015 & 329.400 & 216.733 \\
\hline Put & 86.485 & 90.290 & 90.436 & 87.860 & 133.657 & 141.935 & 143.852 & 120.355 & 280.107 & 289.462 & 320.569 & 132.518 \\
\hline $\mathrm{Put} / \mathrm{S}_{\mathrm{t}}$ & $6.653 \%$ & $6.945 \%$ & $6.957 \%$ & $6.758 \%$ & $10.281 \%$ & $10.918 \%$ & $11.066 \%$ & $9.258 \%$ & $21.547 \%$ & $22.266 \%$ & $24.659 \%$ & $10.194 \%$ \\
\hline$\Delta_{\text {put }}$ & -0.7557 & -0.7094 & -0.7145 & -0.6391 & -0.6423 & -0.5571 & -0.5761 & -0.3433 & -0.5496 & -0.3073 & -0.3877 & -0.2648 \\
\hline
\end{tabular}

Note: 1. All Parameters used in this table are estimated with quarterly data.

2. BS and M-BS stand for Black-Scholes and modified-Black-Scholes, respectively. 
Table 6: The effects of Volatility and Interest Rate on Call Options with Moderate Return Predictability

\begin{tabular}{|c|c|c|c|c|c|c|c|c|c|c|c|c|}
\hline \multirow{3}{*}{$\mathrm{S}_{\mathrm{t}}=1300$} & CRCVCI & SRSVSI & SRSVCI & SRCVSI & CRCVCI & SRSVSI & SRSVCI & SRCVSI & CRCVCI & SRSVSI & SRSVCI & SRCVSI \\
\hline & $\begin{array}{c}\text { - PP } \\
\text { (= }=\mathrm{BS}) \\
\end{array}$ & $-\mathrm{P}$ & $-\mathrm{P}$ & $-\mathrm{P}$ & $\begin{array}{c}-\mathrm{PP} \\
(=\mathrm{BS}) \\
\end{array}$ & $-P$ & $-\mathrm{P}$ & $-P$ & $\begin{array}{c}\text { - PP } \\
\text { (= }=\mathrm{BS}) \\
\end{array}$ & $-P$ & $-\mathrm{P}$ & $-\mathrm{P}$ \\
\hline & \multicolumn{4}{|c|}{$\mathrm{T}-\mathrm{t}=0.25$ year } & \multicolumn{4}{|c|}{$\mathrm{T}-\mathrm{t}=1.00$ year } & \multicolumn{4}{|c|}{$\mathrm{T}-\mathrm{t}=5.00$ years } \\
\hline $\mathrm{E}_{\mathrm{t}}\left(\mathrm{S}_{\mathrm{T}}\right)$ & 1375.82 & 1371.46 & 1370.46 & 1373.73 & 1522.98 & 1500.00 & 1495.43 & 1508.23 & 2618.57 & 2373.27 & 2359.72 & 2404.55 \\
\hline VTM & 0.1453 & 0.1556 & 0.1413 & 0.1460 & 0.1453 & 0.1553 & 0.1454 & 0.1244 & 0.1453 & 0.1548 & 0.1533 & 0.0708 \\
\hline $\mathrm{R}(\mathrm{t}, \mathrm{T})$ & 0.1394 & 0.1262 & 0.1270 & 0.1331 & 0.1394 & 0.1295 & 0.1270 & 0.1353 & 0.1394 & 0.1357 & 0.1270 & 0.1384 \\
\hline \multicolumn{13}{|c|}{ Adjusted Moneyness: $\mathrm{K}=0.95 \mathrm{E}_{\mathrm{t}}\left(\mathrm{S}_{\mathrm{T}}\right)$} \\
\hline K & 1307.03 & 1302.89 & 1301.94 & 1305.05 & 1446.83 & 1425.00 & 1420.66 & 1432.81 & 2487.64 & 2254.61 & 2241.74 & 2284.33 \\
\hline $\mathrm{K} / \mathrm{S}_{\mathrm{t}}$ & 1.005 & 1.002 & 1.001 & 1.004 & 1.113 & 1.096 & 1.093 & 1.102 & 1.914 & 1.734 & 1.724 & 1.757 \\
\hline M-BS Call & 74.440 & 76.474 & 74.324 & 74.546 & 94.878 & 103.584 & 99.109 & 88.625 & 125.116 & 174.523 & 153.745 & 89.254 \\
\hline Call & 74.440 & 73.494 & 77.344 & 74.546 & 94.878 & 86.069 & 79.245 & 88.625 & 125.116 & 84.957 & 72.204 & 89.254 \\
\hline $\mathrm{Call} / \mathrm{S}_{\mathrm{t}}$ & $5.726 \%$ & $5.653 \%$ & $5.950 \%$ & $5.734 \%$ & $7.298 \%$ & $6.621 \%$ & $6.096 \%$ & $6.817 \%$ & $9.624 \%$ & $6.535 \%$ & $5.554 \%$ & $6.866 \%$ \\
\hline$\Delta_{\text {call }}$ & 0.7438 & 0.6817 & 0.4079 & 0.6661 & 0.5953 & 0.4314 & 0.1518 & 0.4119 & 0.4396 & 0.1143 & 0.0600 & 0.1101 \\
\hline \multicolumn{13}{|c|}{ Adjusted Moneyness: $\mathrm{K}=1.00 \mathrm{E}_{\mathrm{t}}\left(\mathrm{S}_{\mathrm{T}}\right)$} \\
\hline K & 1375.82 & 1371.46 & 1370.46 & 1373.73 & 1522.98 & 1500.00 & 1495.43 & 1508.23 & 2618.57 & 2373.27 & 2359.72 & 2404.55 \\
\hline $\mathrm{K} / \mathrm{S}_{\mathrm{t}}$ & 1.058 & 1.055 & 1.054 & 1.057 & 1.172 & 1.154 & 1.150 & 1.160 & 2.014 & 1.826 & 1.815 & 1.850 \\
\hline M-BS Call & 35.020 & 37.614 & 34.444 & 35.173 & 62.890 & 71.044 & 66.241 & 55.221 & 102.852 & 148.568 & 129.410 & 61.000 \\
\hline Call & 35.020 & 35.250 & 20.624 & 35.173 & 62.890 & 54.991 & 20.214 & 55.221 & 102.852 & 59.884 & 18.342 & 61.000 \\
\hline Call $/ \mathrm{S}_{\mathrm{t}}$ & $2.694 \%$ & $2.712 \%$ & $1.586 \%$ & $2.706 \%$ & $4.838 \%$ & $4.230 \%$ & $1.555 \%$ & $4.248 \%$ & $7.912 \%$ & $4.606 \%$ & $1.411 \%$ & $4.692 \%$ \\
\hline$\Delta_{\text {call }}$ & 0.4826 & 0.4467 & 0.1312 & 0.4316 & 0.4594 & 0.3250 & 0.0404 & 0.3043 & 0.3843 & 0.0868 & 0.0153 & 0.0802 \\
\hline \multicolumn{13}{|c|}{ Adjusted Moneyness: $\mathrm{K}=1.05 \mathrm{E}_{\mathrm{t}}\left(\mathrm{S}_{\mathrm{T}}\right)$} \\
\hline K & 1444.61 & 1440.03 & 1438.98 & 1442.42 & 1599.13 & 1575.00 & 1570.21 & 1583.64 & 2749.50 & 2491.94 & 2477.71 & 2524.78 \\
\hline $\mathrm{K} / \mathrm{S}_{\mathrm{t}}$ & 1.111 & 1.108 & 1.107 & 1.110 & 1.230 & 1.212 & 1.208 & 1.218 & 2.115 & 1.917 & 1.906 & 1.942 \\
\hline M-BS Call & 13.075 & 15.159 & 12.494 & 13.200 & 39.709 & 46.771 & 42.194 & 32.079 & 84.144 & 125.975 & 108.490 & 40.073 \\
\hline Call & 13.075 & 14.216 & N/A & 13.200 & 39.709 & 33.859 & N/A & 32.079 & 84.144 & 41.760 & N/A & 40.073 \\
\hline Call/ $/ \mathrm{S}_{\mathrm{t}}$ & $1.006 \%$ & $1.094 \%$ & & $1.015 \%$ & $3.055 \%$ & $2.605 \%$ & & $2.468 \%$ & $6.473 \%$ & $3.212 \%$ & & $3.083 \%$ \\
\hline$\Delta_{\text {call }}$ & 0.2381 & 0.2332 & & 0.2135 & 0.3330 & 0.2306 & & 0.2063 & 0.3329 & 0.0648 & & 0.0561 \\
\hline
\end{tabular}

Note: 1. All Parameters used in this table are estimated with quarterly data.

2. BS and M-BS stand for Black-Scholes and modified-Black-Scholes, respectively.

3. N/A stands for not applicable. when the strike price is too high, SRSVCI-P can't

be computed since the gamma function in the option formula is not well defined. 
Table 7: The effects of Volatility and Interest Rate on Put Options with Moderate Return Predictability

\begin{tabular}{|c|c|c|c|c|c|c|c|c|c|c|c|c|}
\hline \multirow{4}{*}{$S_{t}=1300$} & CRCVCI & SRSVSI & SRSVCI & SRCVSI & CRCVCI & SRSVSI & SRSVCI & SRCVSI & CRCVCI & SRSVSI & SRSVCI & SRCVSI \\
\hline & - PP & $-\mathrm{P}$ & $-\mathrm{P}$ & $-P$ & - PP & $-\mathrm{P}$ & $-\mathrm{P}$ & $-P$ & - PP & $-\mathrm{P}$ & $-\mathrm{P}$ & $-P$ \\
\hline & $(=\mathrm{BS})$ & & & & $(=\mathrm{BS})$ & & & & $(=\mathrm{BS})$ & & & \\
\hline & \multicolumn{4}{|c|}{$\mathrm{T}-\mathrm{t}=0.25$ year } & \multicolumn{4}{|c|}{$\mathrm{T}-\mathrm{t}=1.00$ year } & \multicolumn{4}{|c|}{$\mathrm{T}-\mathrm{t}=5.00$ years } \\
\hline $\mathrm{E}_{\mathrm{t}}\left(\mathrm{S}_{\mathrm{T}}\right)$ & 1375.82 & 1371.46 & 1370.46 & 1373.73 & 1522.98 & 1500.00 & 1495.43 & 1508.23 & 2618.57 & 2373.27 & 2359.72 & 2404.55 \\
\hline VTM & 0.1453 & 0.1556 & 0.1413 & 0.1460 & 0.1453 & 0.1553 & 0.1454 & 0.1244 & 0.1453 & 0.1548 & 0.1533 & 0.0708 \\
\hline $\mathrm{R}(\mathrm{t}, \mathrm{T})$ & 0.1394 & 0.1262 & 0.1270 & 0.1331 & 0.1394 & 0.1295 & 0.1270 & 0.1353 & 0.1394 & 0.1357 & 0.1270 & 0.1384 \\
\hline \multicolumn{13}{|c|}{ Adjusted Moneyness: $\mathrm{K}=0.95 \mathrm{E}_{\mathrm{t}}\left(\mathrm{S}_{\mathrm{T}}\right)$} \\
\hline K & 1307.03 & 1302.89 & 1301.94 & 1305.05 & 1446.83 & 1425.00 & 1420.66 & 1432.81 & 2487.64 & 2254.61 & 2241.74 & 2284.33 \\
\hline $\mathrm{K} / \mathrm{S}_{\mathrm{t}}$ & 1.005 & 1.002 & 1.001 & 1.004 & 1.113 & 1.096 & 1.093 & 1.102 & 1.914 & 1.734 & 1.724 & 1.757 \\
\hline M-BS Put & 14.982 & 17.227 & 13.885 & 15.137 & 56.340 & 58.303 & 53.096 & 42.957 & 190.633 & 144.854 & 167.767 & 58.862 \\
\hline Put & 14.982 & 14.247 & 16.905 & 15.137 & 56.340 & 40.788 & 33.232 & 42.957 & 190.633 & 55.289 & 86.226 & 58.862 \\
\hline Put $/ S_{t}$ & $1.152 \%$ & $1.096 \%$ & $1.300 \%$ & $1.164 \%$ & $4.334 \%$ & $3.138 \%$ & $2.556 \%$ & $3.304 \%$ & $14.664 \%$ & $4.253 \%$ & $6.633 \%$ & $4.528 \%$ \\
\hline$\Delta_{\text {put }}$ & -0.2499 & -0.2022 & -0.2461 & -0.2217 & -0.3800 & -0.1807 & -0.1928 & -0.2083 & -0.4429 & -0.1196 & -0.1690 & -0.1812 \\
\hline \multicolumn{13}{|c|}{ Adjusted Moneyness: $\mathrm{K}=1.00 \mathrm{E}_{\mathrm{t}}\left(\mathrm{S}_{\mathrm{T}}\right)$} \\
\hline K & 1375.82 & 1371.46 & 1370.46 & 1373.73 & 1522.98 & 1500.00 & 1495.43 & 1508.23 & 2618.57 & 2373.27 & 2359.72 & 2404.55 \\
\hline $\mathrm{K} / \mathrm{S}_{\mathrm{t}}$ & 1.058 & 1.055 & 1.054 & 1.057 & 1.172 & 1.154 & 1.150 & 1.160 & 2.014 & 1.826 & 1.815 & 1.850 \\
\hline M-BS Put & 41.996 & 44.813 & 40.388 & 42.201 & 90.595 & 91.651 & 86.079 & 75.421 & 233.592 & 179.112 & 205.946 & 90.784 \\
\hline Put & 41.996 & 42.449 & 26.569 & 42.201 & 90.595 & 75.598 & 40.052 & 75.421 & 233.592 & 90.429 & 94.877 & 90.784 \\
\hline Put $/ S_{t}$ & $3.230 \%$ & $3.265 \%$ & $2.044 \%$ & $3.246 \%$ & $6.969 \%$ & $5.815 \%$ & $3.081 \%$ & $5.802 \%$ & $17.969 \%$ & $6.956 \%$ & $7.298 \%$ & $6.983 \%$ \\
\hline$\Delta_{\text {put }}$ & -0.5112 & -0.4314 & -0.3425 & -0.4506 & -0.5159 & -0.2680 & -0.2149 & -0.2972 & -0.4982 & -0.2150 & -0.1711 & -0.1930 \\
\hline \multicolumn{13}{|c|}{ Adjusted Moneyness: $\mathrm{K}=1.05 \mathrm{E}_{\mathrm{t}}\left(\mathrm{S}_{\mathrm{T}}\right)$} \\
\hline K & 1444.61 & 1440.03 & 1438.98 & 1442.42 & 1599.13 & 1575.00 & 1570.21 & 1583.64 & 2749.50 & 2491.94 & 2477.71 & 2524.78 \\
\hline $\mathrm{K} / \mathrm{S}_{\mathrm{t}}$ & 1.111 & 1.108 & 1.107 & 1.110 & 1.230 & 1.212 & 1.208 & 1.218 & 2.115 & 1.917 & 1.906 & 1.942 \\
\hline M-BS Put & 86.485 & 88.804 & 101.529 & 101.223 & 133.657 & 133.267 & 127.881 & 118.147 & 280.107 & 216.733 & 247.538 & 130.032 \\
\hline Put & 86.485 & 87.860 & N/A & 101.223 & 133.657 & 120.355 & N/A & 118.147 & 280.107 & 132.518 & N/A & 130.032 \\
\hline $\mathrm{Put} / \mathrm{S}_{\mathrm{t}}$ & $6.653 \%$ & $6.758 \%$ & & $7.786 \%$ & $10.281 \%$ & $9.258 \%$ & & $9.088 \%$ & $21.547 \%$ & $10.194 \%$ & & $10.002 \%$ \\
\hline$\Delta_{\text {put }}$ & -0.7557 & -0.6391 & & -0.5359 & -0.6423 & -0.3433 & & -0.3765 & -0.5496 & -0.2648 & & -0.2349 \\
\hline
\end{tabular}

Note: 1. All Parameters used in this table are estimated with quarterly data.

2. BS and M-BS stand for Black-Scholes and modified-Black-Scholes, respectively.

3. N/A stands for not applicable. when the strike price is too high, SRSVCI-P can't

be computed since the gamma function in the option formula is not well defined. 
Exhibit 1: Effects of Maturity on Option Prices under Different Levels of Return Predictability
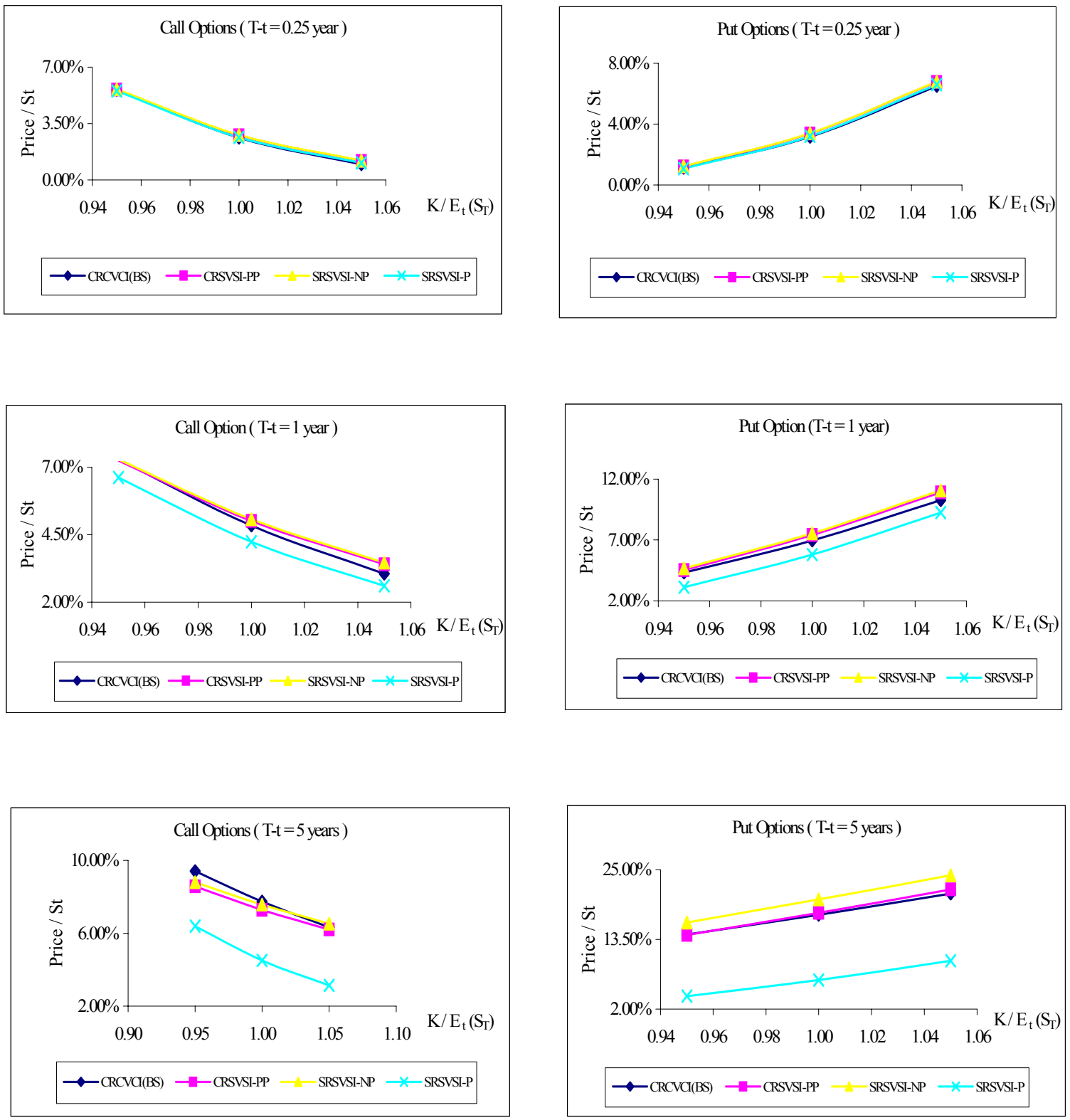
Exhibit 2: Effects of Maturity on Delta Hedging under Different Levels of Return Predictability
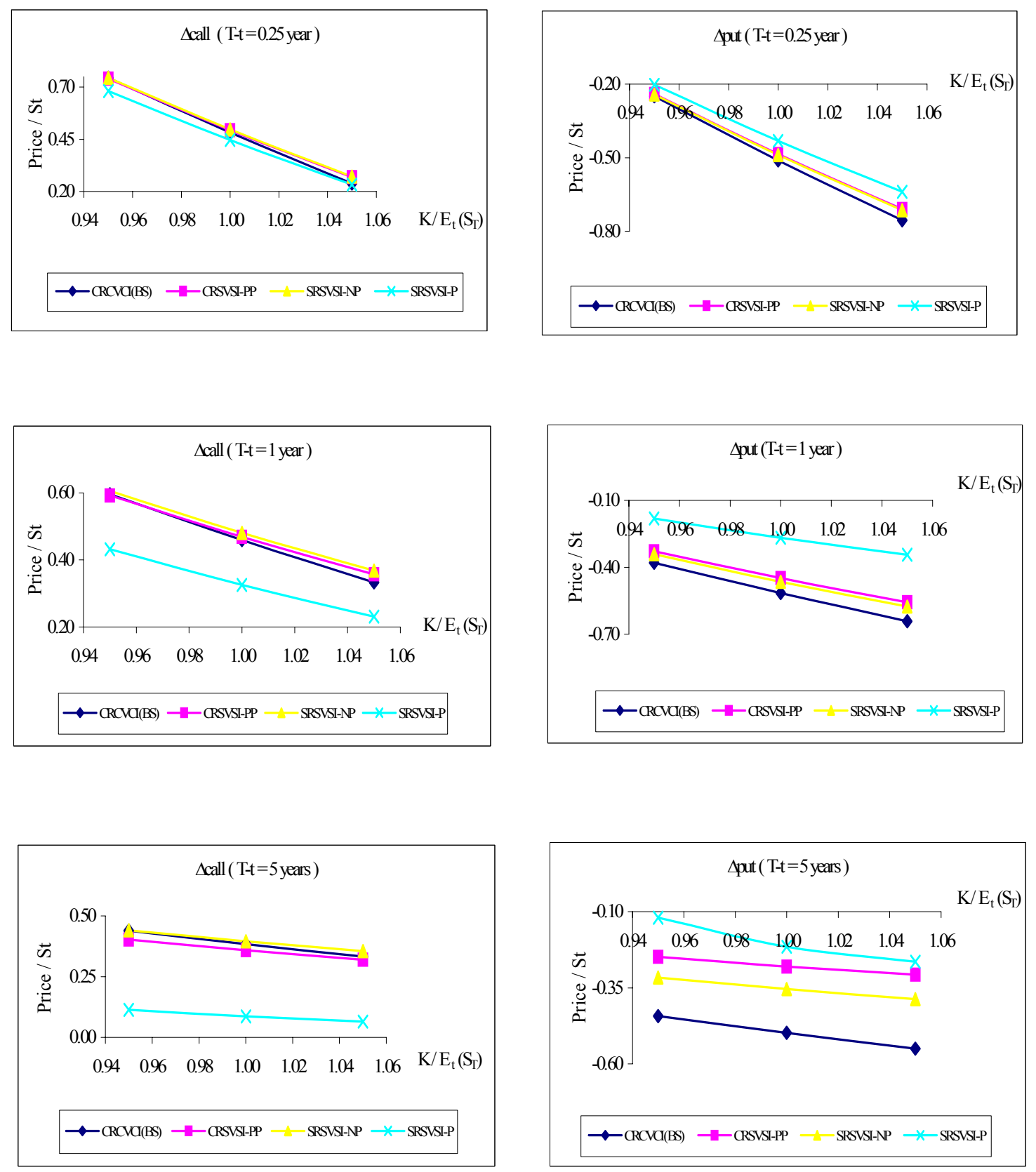